\title{
Experimentally Determined Equivalent Roughness Values For Two Types of Longitudinal Straight Duct Produced by a Small Company
}

\author{
Raphael W. Alwin Dodrill \\ West Virginia University
}

Follow this and additional works at: https://researchrepository.wvu.edu/etd

\section{Recommended Citation}

Dodrill, Raphael W. Alwin, "Experimentally Determined Equivalent Roughness Values For Two Types of Longitudinal Straight Duct Produced by a Small Company" (2013). Graduate Theses, Dissertations, and Problem Reports. 445.

https://researchrepository.wvu.edu/etd/445

This Thesis is protected by copyright and/or related rights. It has been brought to you by the The Research Repository @ WVU with permission from the rights-holder(s). You are free to use this Thesis in any way that is permitted by the copyright and related rights legislation that applies to your use. For other uses you must obtain permission from the rights-holder(s) directly, unless additional rights are indicated by a Creative Commons license in the record and/ or on the work itself. This Thesis has been accepted for inclusion in WVU Graduate Theses, Dissertations, and Problem Reports collection by an authorized administrator of The Research Repository @ WVU. For more information, please contact researchrepository@mail.wvu.edu. 


\title{
Experimentally Determined Equivalent Roughness Values For Two Types of Longitudinal Straight Duct Produced by a Small Company
}

\author{
Raphael W. Alwin Dodrill \\ Thesis submitted to the \\ College of Engineering and Mineral Resources at \\ West Virginia University \\ in partial fulfillment of the requirements \\ for the degree of \\ Master of Science \\ in \\ Mechanical Engineering \\ Steven E. Guffey Ph.D. CIH, Chair \\ Larry E. Banta Ph.D. PE \\ Kenneth H. Means Ph.D. PE
}

Department of Mechanical and Aerospace Engineering

Morgantown, West Virginia

2012

Key Words:

Duct Friction; Darcy Friction; Colebrook

Copyright 2012 Raphael W. Alwin Dodrill 


\title{
Abstract \\ Experimentally Determined Equivalent Roughness Values For Two Types of Longitudinal Straight Duct Produced by a Small Company
}

\author{
Raphael W. Alwin Dodrill
}

This study evaluates the static pressure losses due to friction in longitudinal straight ducts. These losses are related to the flow properties (velocity, density, etc.) by means of the Darcy friction factor, $f$. In the case of hydraulically smooth wall conditions the $f$ value is related to the Reynold's number $(\mathrm{Re})$, while for rough conditions it is dominated by the relative roughness $\left(\varepsilon / \mathrm{D}_{\mathrm{h}}\right)$. The Colebrook equation is often used to determine the $f$ value as it also provides a reasonable value when the flow is in the transient region between hydraulically smooth and rough wall conditions.

Experimental data was collected for these galvanized steel ducts over a range of 1500$5000 \mathrm{fpm}$ with nominal diameters of 4-8 inches. It was found that hydraulically smooth conditions could be applied for all the tested cases. However, the hydraulically smooth predictive equations resulted in underestimating the pressure losses, while applying an effective roughness value of $\varepsilon=0.0001$ feet (determined from a recursive back calculation from the experimental data) yielded better predictions of the pressure losses. A regression analysis indicated that both the hydraulic diameter $\left(D_{h}\right)$ and Re were statistically significant factors in determining the $f$-value. The regression model for the $f$-value based on $\mathrm{Dh}$ and Re resulted in a higher coefficient of determination $\left(\mathrm{R}^{2}\right)$ than a model based on Re alone. The regression model was applied to the dataset and resulted in less error than applying the Colebrook equation with an effective roughness value of $\varepsilon=0.0001$ feet.

\section{Acknowledgements}

The author wishes to thank the following for their help and support: Nordfab for supplying the necessary ductwork, the AEC members (Dr. Steven E. Guffey, Dr. Larry E Banta, and Dr. Kenneth H. Means) for their input and advice, and Chris Judy and Ahmed El-Sotouhy for aiding in assembling the test system. 


\section{Table of Contents}

Introduction \& Background 1

Literature Review 4

Apparatus

Experimental System

Measurement Apparatus $\quad 10$

Data Acquisition $\quad 13$

$\begin{array}{lr}\text { Methods } & 13\end{array}$

$\begin{array}{lr}\text { Experimental } & 13\end{array}$

$\begin{array}{lr}\text { Calculations } & 14\end{array}$

Results \& Discussion $\quad 15$

Experimental Uncertainty 25

$\begin{array}{ll}\text { Conclusions } & 27\end{array}$

Bibliography $\quad 29$

Appendix A - Calculations 31

Appendix B - Excel User Defined Functions 33 


\section{List of Figures}

Figure 1 - View of the test section $\quad 7$

Figure 2-View of test section inlet $\quad 8$

Figure 3-Schematic of test section 8

Figure 4 - Flanged and QUICK-FIT duct sections 9

$\begin{array}{ll}\text { Figure 5 - Airflow PVM } 100 & 11\end{array}$

Figure 6 - Dwyer 1425 Hook Gague 11

$\begin{array}{lr}\text { Figure } 7 \text { - Measurement Location } & 12\end{array}$

Figure 8-Measurement Location and Slide-gate Damper $\quad 12$

Figure 9-Velocity pressure profiles for 8" ducts 16

Figure 10 - Velocity pressure profiles normalized by $\mathrm{VP}_{\text {avg }} \quad 16$

$\begin{array}{ll}\text { Figure } 11 \text { - Observed pressure losses for ME section } & 17\end{array}$

$\begin{array}{ll}\text { Figure } 12-\text { Hydraulically smooth predictor comparisons } & 18\end{array}$

Figure 13- Log-Log $\mathrm{SPf}_{\mathrm{ME}} / \mathrm{L}_{\mathrm{ME}}$ Vs Re $\quad 20$

Figure 14 - Pressure loss per ft vs Re for mid-end region 22

\section{List of Tables}

Table 1 - Friction Equations

Table 2 - Actual duct diameters (inches) and Measurement locations (feet and diameters)

Table 3 - Test velocities $\quad 10$

$\begin{array}{ll}\text { Table } 4 \text { - Idelchick equations for observed data } & 18\end{array}$

Table 5 - Mean absolute roughness values for each nominal diameter tested $\quad 19$

Table 6 - Regression coefficients for $f$-value log predictor model 20

Table 7 - Regression coefficients for pressure loss per foot log predictor model 21

Table $8-\%$ Error in predicted $\mathrm{SP}_{\mathrm{f}} / \mathrm{L}$ over the mid-end region 23

Table 9 - Error (in H2O) for Mid-End region 23

Table 10 - Average Error of $\mathrm{SP}_{\mathrm{f}}$ vs Target $\mathrm{V}_{\text {avg }}$ for the Mid-End Region 24

Table 11 - Mean $F_{h}$ values for duct type and diameter determined at hood, mid, and $\begin{array}{ll}\text { end measurement locations } & 24\end{array}$

Table 12 - 26-Aug-2008 Calibration check of PVM-100 25

Table 13 - Uncertainties of measured values $\quad 26$

Table 14 - Uncertainties for computed results 27 


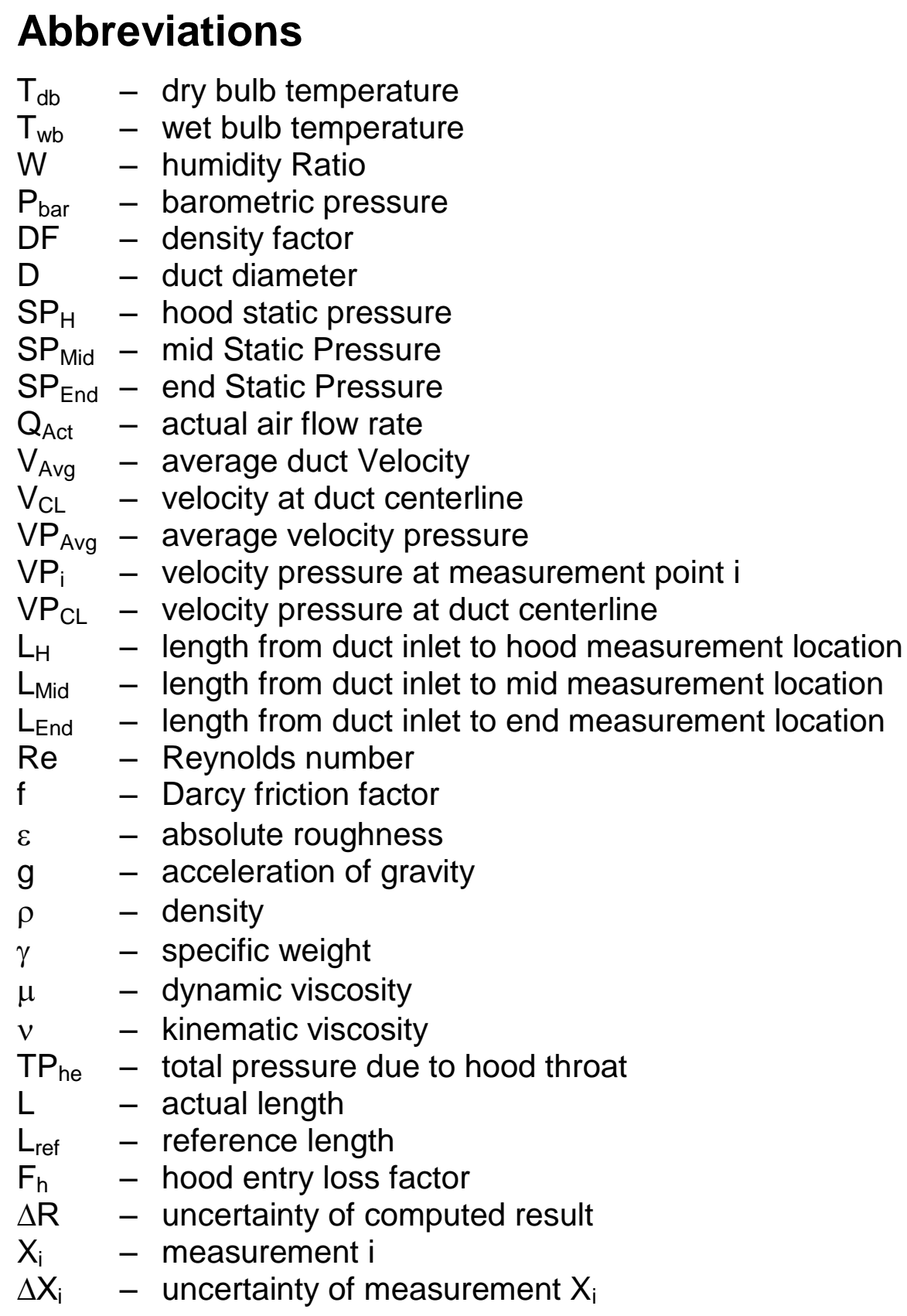




\section{Introduction \& Background}

For duct design and application it is desirable to be able to estimate the pressure losses in the air flow based on the dimensions, material, and the physical properties of the duct as well as the velocity and density of the airflow through the duct.. The Darcy friction formula (Equation 1) relates the pressure losses due to friction in straight pipes to the total length, hydraulic diameter, the dynamic or velocity pressure, and the Darcy friction factor. The Darcy friction factor is dependent on the pipe material, the fluid, as well as the flow regime (hydraulically smooth, fully turbulent a.k.a. rough pipe, or the transition region).

$$
T P_{F}=S P_{F}=\frac{f \cdot L \cdot V P}{D_{h}}
$$

Where:

$\mathrm{TP}_{\mathrm{F}}=$ total pressure loss due to friction

$\mathrm{SP}_{\mathrm{F}}=$ static pressure loss due to friction

$f=$ Darcy friction factor

$\mathrm{L}=$ length of duct

$\mathrm{D}_{\mathrm{h}}=$ hydraulic diameter of the duct (must have the same units as $\mathrm{L}$ )

$\mathrm{VP}=$ dynamic or velocity pressure (same units as the static/total pressure due to friction)

Blasius (1913) stated that the pressure loss in a pipe was given by the relation in Equation 2, which is a different form of the Darcy formula listed above. He concluded that for hydraulically smooth ducts the $f$ value is a function of the Reynolds number given in Equation 3.

$$
T P_{F}=f \gamma \frac{L}{D_{h}} \frac{V_{a v g}{ }^{2}}{2 g}
$$

Where:

$$
\begin{aligned}
& g=\text { acceleration of gravity } \\
& \gamma=\text { specific weight }
\end{aligned}
$$




$$
\operatorname{Re}=\frac{\rho_{s l} \cdot D F \cdot V_{a v g} \cdot D_{h}}{\mu}=\frac{V_{a v g} D_{h}}{v}
$$

Where:

$$
\begin{aligned}
\rho_{\mathrm{s} 1} & =\text { air density at sea level } \\
\mathrm{DF} & =\text { density factor } \\
\mathrm{V}_{\mathrm{avg}} & =\text { average velocity } \\
\mathrm{D}_{\mathrm{h}} & =\text { hydraulic diameter of the duct } \\
\mu & =\text { dynamic viscosity } \\
\nu & =\text { kinematic viscosity }
\end{aligned}
$$

In rough pipe conditions the friction losses can be attributed to the absolute roughness of the pipe $(\varepsilon)$ though it is often expressed in terms of the relative roughness $\left(\varepsilon / D_{h}\right)$. These roughness terms generally refer to the "effective" roughness, which accounts for pipe joints and manufacturing technique as well as the actual material roughness.

It is important to determine the appropriate flow regime and select the predictive equation that will provide the best estimate of the friction factor. Blasius (Table 1, Equation 4), Prandtl (Table 1, Equation 5), and Nikuradse (Table 1, Equation 6) proposed predictor equations for hydraulically smooth pipes. The Nikuradse equation is a simplified form of the Prandtl equation that does not require an iterative solution yet provides nearly identical results.

Prandtl also characterized the friction factor for rough pipe theory (Table 1, Equation 7). Yet it was rather difficult to characterize the flow in the transition region between hydraulically smooth and rough pipe conditions. Colebrook (1939) proposed a solution for the transition region by using $\mathrm{y}_{1}=\mathrm{f}(\varepsilon, 1 / \mathrm{Re})$ and finding the limits of integration that satisfy the smooth and rough pipe laws (presented by Prandtl). He then added those lower limits of integration, resulting in the Colebrook equation (Table 1, Equation 8). The Colebrook formula requires a computationally inconvenient iterative solution. Guffey (1992) stated that Haaland proposed a simpler formula (Table 1, Equation 9) that approximates $f$ values within $2 \%$ of the value predicted by the Colebrook equation without any iteration.

If fully developed rough pipe flow regime is assumed to be applicable for the data set, the Prandtl rough pipe equation and the Colebrook equation are equivalent and the Haaland 
equation offers a similar, yet slightly lower, value for the $f$ value. This shows that when not subjected to a transition flow regime the Nikuradse and Prandtl rough pipe equations are easiest to apply since they do not require an iterative solution and will predict $f$ values nearly identical to those obtained from the universally applicable Colebrook equation.

Table 1 - Friction Equations

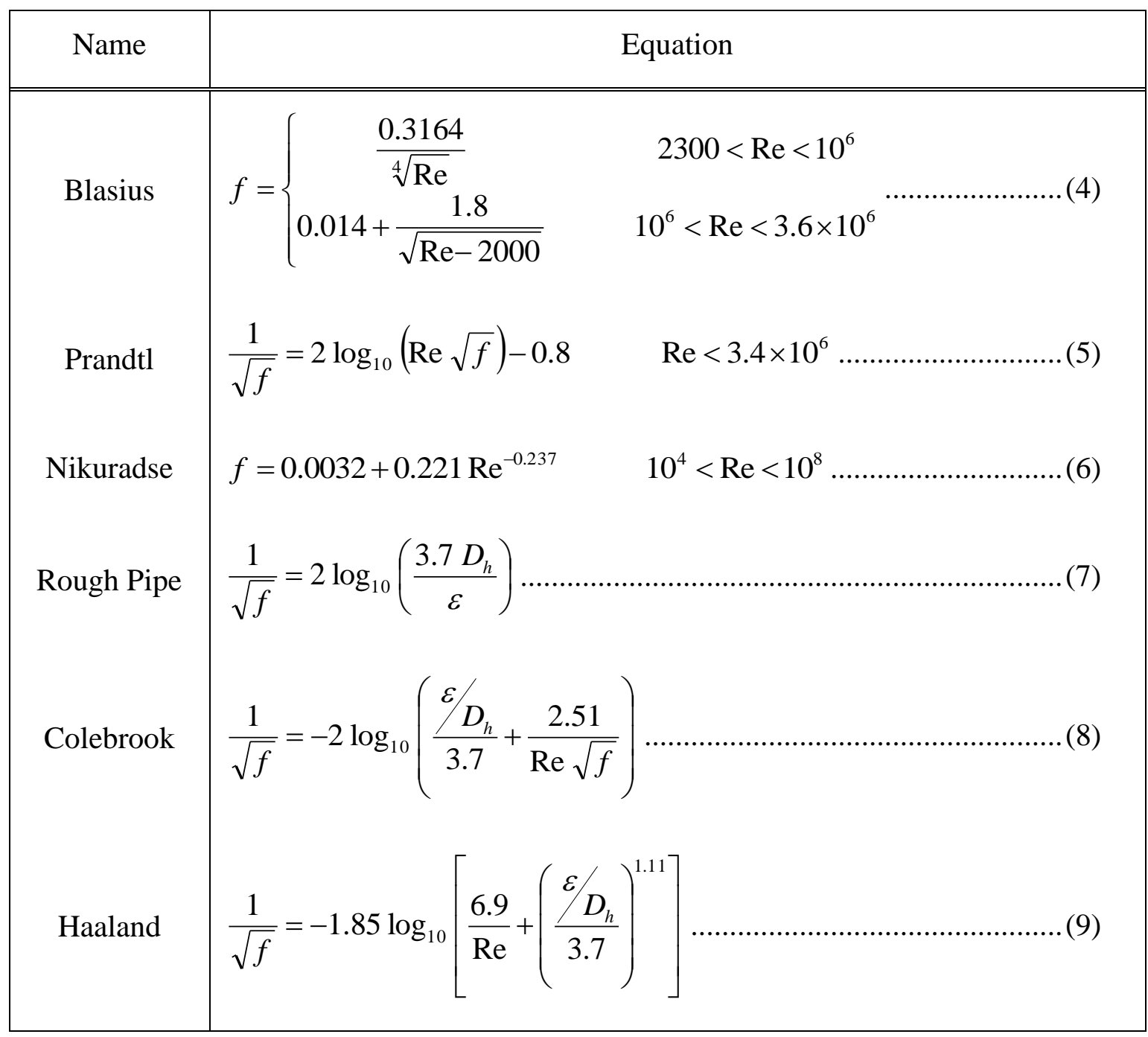

For many applications it is common practice to utilize the Colebrook equation for estimating the friction factor. The Colebrook equation can also be used to obtain the effective roughness from experimentally determined $f$ values. Colebrook (1939) stated that for certain pipe materials (e.g., drawn brass, lead), with low roughness values, the pipes can be regarded as hydraulically smooth flow (i.e., $\varepsilon=0$ ). 
Idelchik (1986) further evaluated this premise and specified that hydraulically smooth conditions are applicable when the viscous boundary layer is thicker than the height of the absolute roughness. This is the case when the conditions in Equation 10 are satisfied:

$$
\frac{\varepsilon}{D_{h}} \leq \frac{181 \log (\mathrm{Re})-16.4}{\operatorname{Re}}
$$

It is appropriate to assume rough pipe conditions if the conditions specified in Equation 11 are met:

$$
\operatorname{Re}>\frac{560}{\varepsilon / D_{h}}
$$

If the conditions of neither Equation 10 nor 11 are met, then the flow should be assumed to be in the transition regime and the Colebrook equation should be used.

The purpose of this study is to evaluate the pressure losses due to friction in long straight ducts and determine the effects of the flow properties and effective roughness on the pressure loss. Various published predictive models for the $f$-value were compared to log models (generated from the experimental dataset) to determine which model will yield predicted pressure losses closest to the observed experimental values.

\section{Literature Review}

Blasius (1913) recommended that the formula listed as Equation 2 be used to determine the pressure losses in pipes. He performed a dimensional analysis in the pressure loss formula. As the pressure loss is given in terms of $\mathrm{L}$ and $\mathrm{D}_{\mathrm{h}}$, he proposed that the $f$ value would be a function of $\mathrm{VD} / v$ (i.e., $\mathrm{Re}$ ). In a series of experiments on drawn brass pipes with various flow conditions, he showed that for cases with equal Reynolds number the $f$ values were the same. This was apparent when comparing $10 \mathrm{~m} / \mathrm{s}$ flow in a $5 \mathrm{~mm}$ ID pipe and $0.5 \mathrm{~m} / \mathrm{s}$ flow in a $100 \mathrm{~mm}$ ID pipe at the same temperature and kinematic viscosity. He fitted a curve to his experimental data resulting in Equation 4. He also compared $f$ value data published by Saph and Schoder (1903) to those predicted by his proposed equation. He found that the predicted values were within $\pm 2 \%$ of the published values. 
Blasius also suggested that for rough pipes the friction factor would also be affected by the roughness of the pipe. Prandtl (1933) plotted experimentally determined values of $\frac{1}{\sqrt{f}}$ collected by Nikuradse (unpublished) along with a plotted curve of values computed by the Blasius formula (Equation 4). Visual examination of the plot shows that the Blasius formula worked well for $1.5<\log (\operatorname{Re})<2.75$. Outside that range, the values predicted by the Blasius formula increasingly deviated from the experimental values. $\mathrm{He}$ derived more accurate formulas for predicting $f$ values for the cases of hydraulically smooth and rough ducts. However, the Prandtl formula for hydraulically smooth conditions (Equation 5) required an iterative solution for the friction factor. Nikuradse (1933) proposed a simplified version (Equation 6) that does not require an iterative solution. The $f$-values computed by the Nikuradse equation were found to be within $3 \%$ of the values provided by the Prandtl formula.

According to Wright (1945), in 1938 the ASHVE Research Laboratories began a study of resistance to flow in sheet metal ducts. Using data collected on 4, 8, and 24 inch round ducts, the Laboratory presented a paper in 1939 containing friction charts for round pipes with 40 joints per $100 \mathrm{ft}$. Wright stated that the $f$-values read from the ASHVE charts were somewhat lower than the values in general use, and the values for ducts without joints were substantially lower than previously published data. Wright stated that many practitioners preferred using the friction charts as they could obtain values visually without performing complex calculations, yet were not confident in using the values from the ASHVE charts. For that reason, Wright developed a friction chart with values computed from Colebrook's equation for standard sea-level conditions and an assumed roughness $5 \times 10^{-4} \mathrm{ft}$. He believed this to be an appropriate roughness value for clean, round galvanized sheet metal duct with 40 slip joints per $100 \mathrm{ft}$, the type for which the ASHVE charts were published. He also noted that the "ultimate smoothness" obtainable for galvanized sheet metal ducts is on the order of $\varepsilon=5 \times 10^{-6} \mathrm{ft}$, which is about the same as smooth drawn tubing. He compared $f$ values published in various sources to values read from the family of curve on his chart. He found that the $f$-values read from the chart deviated from the observed value by $\pm 5-10 \%$. 
Hutchinson (1953) presumed that the absolute roughness may change with duct diameter. He conducted a study to characterize the effect of diameter on the effective absolute roughness. His data was taken from tests of $3 \mathrm{ft}$ long duct sections with 3, 6, and 12 incn diameters with velocities ranging from $1325 \mathrm{fpm}$ to $5940 \mathrm{fpm}$. For the 8 test points on aluminum ducts he found $\varepsilon$ values between $1 \times 10^{-4} \mathrm{ft}$ and $2 \times 10^{-4} \mathrm{ft}$ with an average around $1.5 \times 10^{-4} \mathrm{ft}$ at each diameter. For the 3 test points $(1310 \mathrm{fpm}, 1932 \mathrm{fpm}$, and $5850 \mathrm{fpm}$ ) on 6 in Galvanized iron pipes he found an average roughness of $\varepsilon=5.3 \times 10^{-4} \mathrm{ft}$. This supported Wright's assumed absolute roughness value of $5 \times 10^{-4} \mathrm{ft}$ for galvanized iron ducts.

It is difficult to accurately read values from the Wright friction chart. This is primarily due to the non-linear scales used on the chart. Guffey (1992) proposed a set of tables from which the $f$ value can easily be read. He utilized the Colebrook equation to compute the friction factor based on duct diameter and mean velocity for a specified roughness value. These tables, like the Wright chart, utilize standard sea-level conditions.

Idelchik (1986) characterized the various types of flow through straight pipes. He provided an extensive table of ranges for recommended roughness values for ducts based on their material, manufacturing techniques, as well as previous wear. Based on the absolute roughness values, the applicable $f$ value predictor equation could be selected by means of the inequalities given in Equations 10 and 11.

McLoone et al. (1993) studied the size and shape of suction hoods to evaluate their effects on entry loss factors $\left(F_{h}\right)$. To do so, they first determined the estimated pressure loss per unit length of duct in a section located 40 to 100.3 diameters downstream of the entry location. The estimated pressure loss per foot was multiplied by the length of duct to a given measurement locations and subtracted from the static pressure measurement to determine the $F_{h}$ at each location. Their findings showed that the entry effects are greatest near the entry as a result of the vena contracta. Subsequently the entry loss factor increased but did not appear to have reached a plateau after $20 \mathrm{D}$ downstream of the inlet. Therefor the author concluded that (particularly in smooth ducts) entry effects are still present past $20 \mathrm{D}$ from the inlet. Their study also showed that the entry loss factors decreased with increasing air velocity. 


\section{Apparatus}

\section{Experimental System}

For the purpose of this research, an exhaust ventilation test system was constructed comprising of an inlet section, measurement section, fan unit, and exhaust (see Figure 1). This system was located in a high bay with intake from the room environment and exhaust to the outside air. The inlet consisted of a bare end of a straight duct section with no obstacles in close proximity to the opening (see Figure 2). The inlet and measurement sections were comprised of a straight duct section about $50 \mathrm{ft}$ long with nominal test diameters ranging from 4 to 8 inches. Static pressure measurements were taken at 3 locations along the test section ("Hood", "Mid", and "End") and a velocity pressure traverse was performed near the end of the measurement section (see schematic in Figure 3). Air flow velocity adjustments were achieved with a slide gate damper located after the measurement section. The system airflow was provided by an Aerovent (Minneapolis, MN) model 315 BI-SWCB-3435-3 backwards inclined centrifugal fan.

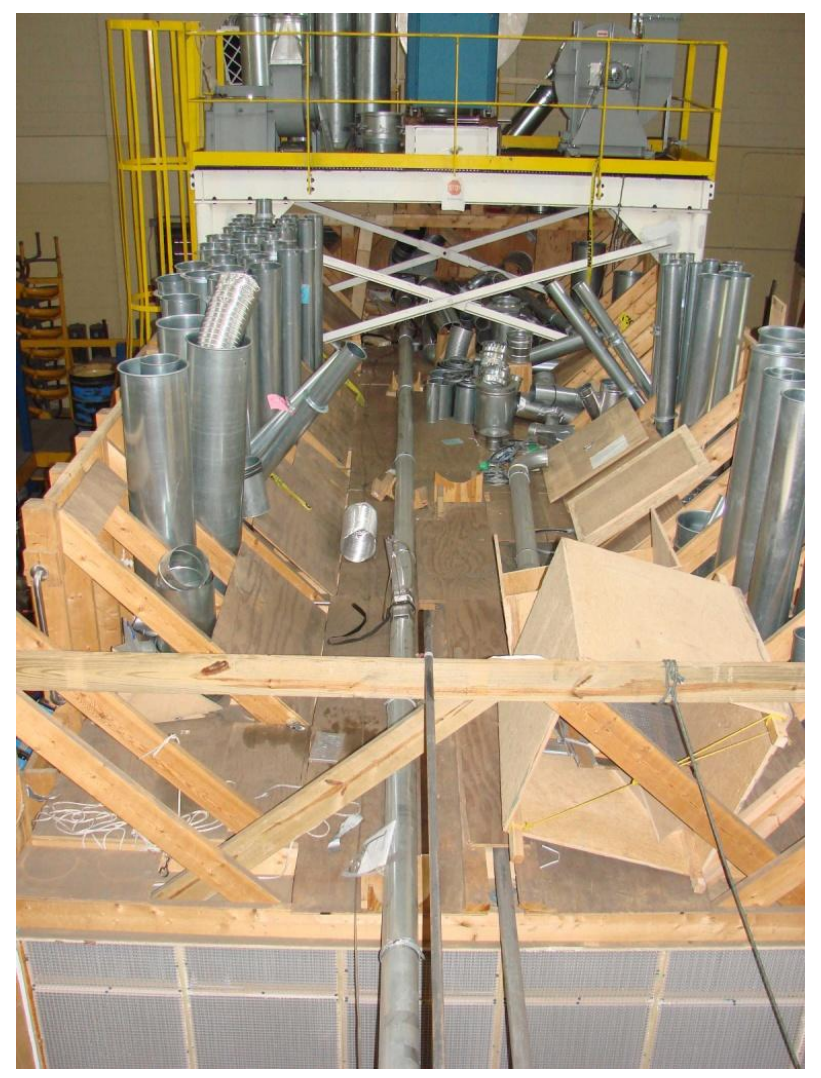

Figure 1 - View of the test section 


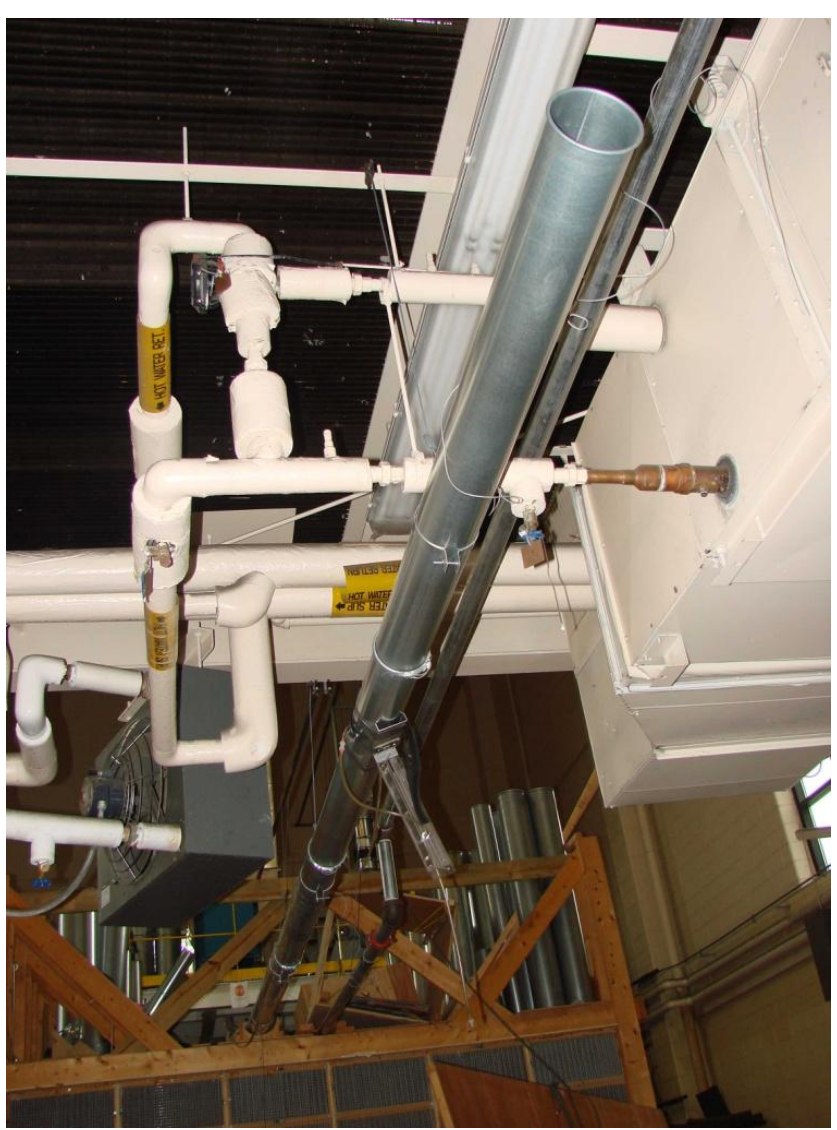

Figure 2 - View of test section inlet

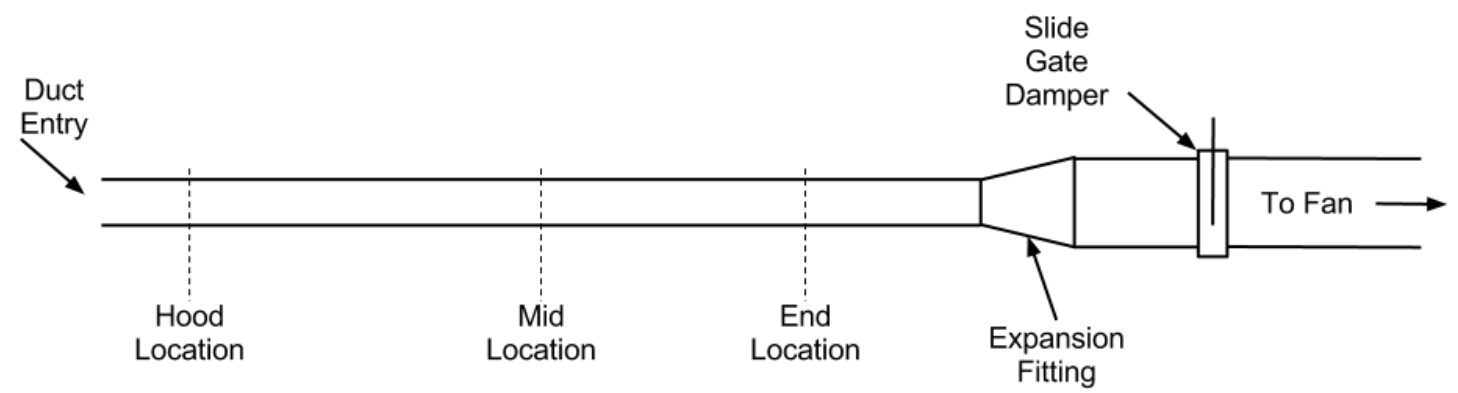

Figure 3 - Schematic of test section

The duct sections used for the interchangeable test section were roughly $5 \mathrm{ft}$ long $20 \mathrm{Ga}$ galvanized steel manufactured by Nordfab®. Two duct types were selected for this study, namely "Flanged" and "QUICK-FIT" (see Figure 4). The QUICK-FIT sections were made of rolled galvanized steel with laser welded seams and rolled ends, which allowed the sections to be clamped together. The Flanged sections were locked form 
construction where the seams were subsequently laser welded. The flanged sections are secured by 6 bolts that pass through free flanges on each duct section.

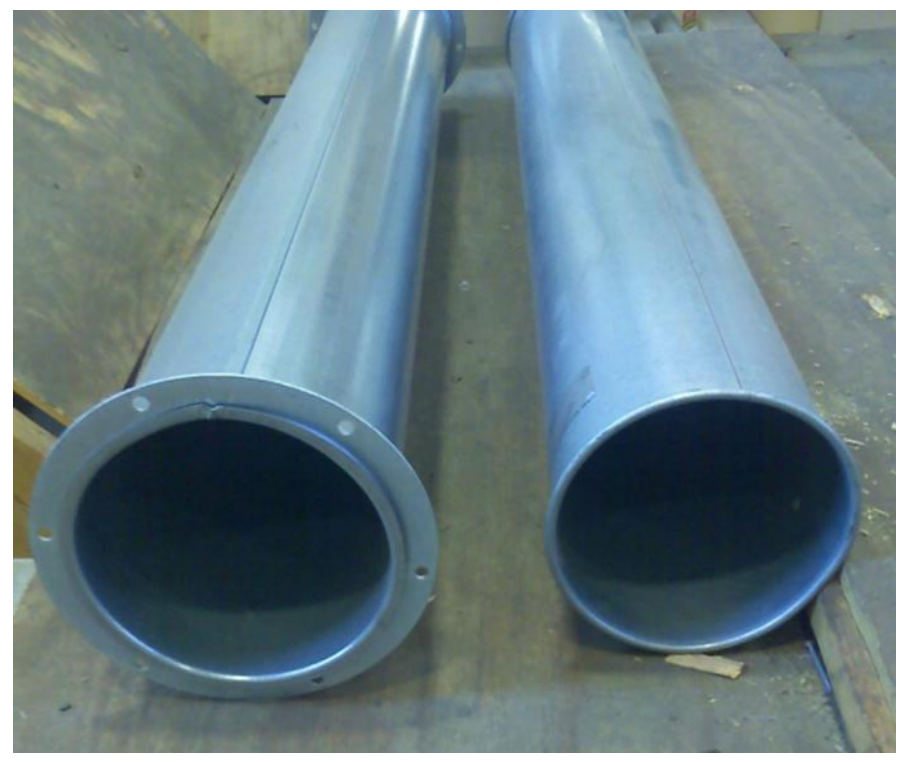

Figure 4 - Flanged and QUICK-FIT duct sections

The duct sections were assembled without the use of gaskets or caulking at the joints as this is how they are designed to be installed in a commercial exhaust ventilation system. This was desirable to evaluate the pressure losses in a real-world environment rather than using idealized laboratory conditions. The majority of the duct sections used in this study had been stored in an environment with a fair amount of airborne coal dust; since it was desirable to have test conditions that were as close as possible to an industrial setting, any coal dust that had settled on the ducts was left in place as this would be representative of fine dust/particulates that would electrostatically cling to the walls of an industrial ventilation system. The nominal duct sizes along with the respective actual ID and measurement locations in number of diameters are presented in Table 2. A pilot run was conducted using an 8 in duct section was performed to evaluate the effective range of duct velocities; this data was used to determine the selected test conditions listed in Table 3. 
Table 2 - Actual duct diameters (inches) and Measurement locations (feet and diameters)

\begin{tabular}{|c|c|c|c|c|c|c|c|c|c|c|}
\hline \multirow[b]{2}{*}{$\begin{array}{l}\text { Duct } \\
\text { Type }\end{array}$} & \multirow{2}{*}{$\begin{array}{c}\text { Nominal } \\
\text { Diameter } \\
\text { (in) }\end{array}$} & \multirow{2}{*}{$\begin{array}{c}\text { Actual } \\
\text { Diameter } \\
\text { (in) }\end{array}$} & \multicolumn{2}{|c|}{$\begin{array}{l}\text { Test Section } \\
\text { Length }\end{array}$} & \multicolumn{2}{|c|}{ Hood location } & \multicolumn{2}{|c|}{ Mid Location } & \multicolumn{2}{|c|}{$\begin{array}{l}\text { End/pitot } \\
\text { traverse }\end{array}$} \\
\hline & & & $(\mathrm{ft})$ & (D) & $(\mathrm{ft})$ & (D) & (ft) & (D) & (ft) & (D) \\
\hline \multirow{5}{*}{$\begin{array}{l}\bar{D} \\
\mathbb{D} \\
\frac{\pi}{\pi} \\
\leftarrow\end{array}$} & 4 & 3.875 & 60.25 & 186.6 & 6.625 & 20.5 & 28.1 & 87.0 & 47.35 & $\overline{146.6}$ \\
\hline & 5 & 4.875 & 60.25 & 148.3 & 6.6 & 16.3 & 28.1 & 69.2 & 47.35 & 116.6 \\
\hline & 6 & 5.875 & 60.25 & 123.1 & 6.6 & 13.5 & 28 & 57.4 & 47.35 & 96.7 \\
\hline & 7 & 6.875 & 60.25 & 105.2 & 6.625 & 11.6 & 28.1 & 49.1 & 47.35 & 82.7 \\
\hline & 8 & 7.875 & 60.25 & 91.8 & 6.625 & 10.1 & 28.1 & 42.8 & 47.35 & 72.2 \\
\hline \multirow{5}{*}{ 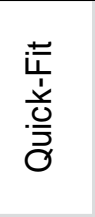 } & 4 & 3.875 & 59.25 & 183.5 & 6.521 & 20.2 & 27.56 & 85.4 & 46.35 & 143.5 \\
\hline & 5 & 4.875 & 59.25 & 145.8 & 6.521 & 16.1 & 27.56 & 67.8 & 46.35 & 114.1 \\
\hline & 6 & 5.875 & 59.25 & 121.0 & 6.521 & 13.3 & 27.56 & 56.3 & 46.35 & 94.7 \\
\hline & 7 & 6.875 & 59.25 & 103.4 & 6.521 & 11.4 & 27.56 & 48.1 & 46.35 & 80.9 \\
\hline & 8 & 7.875 & 59.25 & 90.3 & 6.521 & 9.9 & 27.56 & 42.0 & 46.35 & 70.6 \\
\hline
\end{tabular}

Table 3 - Test velocities

\begin{tabular}{|c|c|c|}
\hline $\mathrm{V}_{\text {target }}(\mathrm{fpm})$ & $\mathrm{V}_{\mathrm{cl}}$ (fpm) & $\mathrm{VP}_{\mathrm{cl}}$ (in w.g.) \\
\hline \hline 1585 & 1761 & 0.19 \\
\hline 1871 & 2079 & 0.27 \\
\hline 2208 & 2453 & 0.37 \\
\hline 2606 & 2896 & 0.51 \\
\hline 3076 & 3418 & 0.72 \\
\hline 3631 & 4034 & 1.00 \\
\hline 4285 & 4762 & 1.39 \\
\hline 5058 & 5620 & 1.94 \\
\hline
\end{tabular}

\section{Measurement Apparatus}

The static pressures and velocity pressures were measured with an Airflow (High Wycombe, United Kingdom) PVM-100 digital manometer (Figure 5) and a Dwyer (Michigan City, IN) 1/8 inch diameter pitot-static tube. The PVM-100 was factory calibrated when purchased in Apr-07. A custom made device was used to hold and maintain proper alignment of the pitot-static tubes (Guffey, 1990), shown in Figure 7, this device has interchangeable scales that are notched to the appropriate insertion depths for each duct diameter based on a 10 point log-Tchebycheff traverse. The PVM-100 has a specified accuracy of $\pm 1 \%$ of Reading \pm 1 digit. The calibration of the PVM-100 was verified using a Dwyer No 1425 hook gauge (Figure 6).

The PVM-100 was set for a slow response while recording the pressures. This setting averages 4 samples over a 3 second time period and displays the average while also printing the displayed values to a serial port, which allowed them to be directly recorded 
to a PC using a data acquisition program. The target duct velocity was achieved by adjusting a damper located between the test section and the fan (see Figure 8).

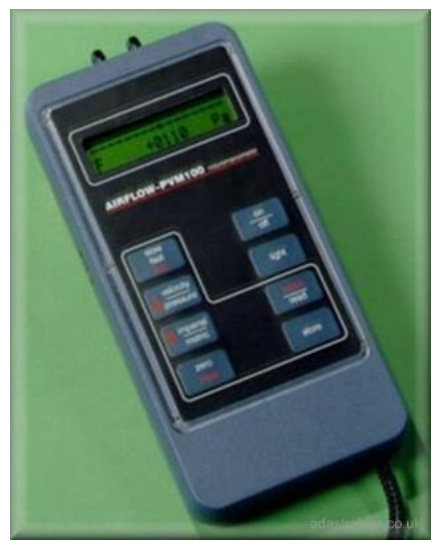

Figure 5 - Airflow PVM 100

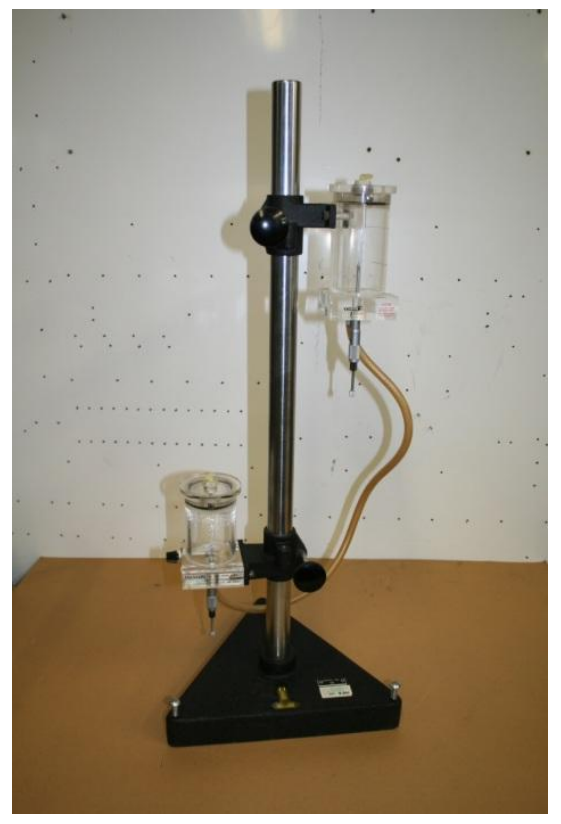

Figure 6 - Dwyer 1425 Hook Gague 


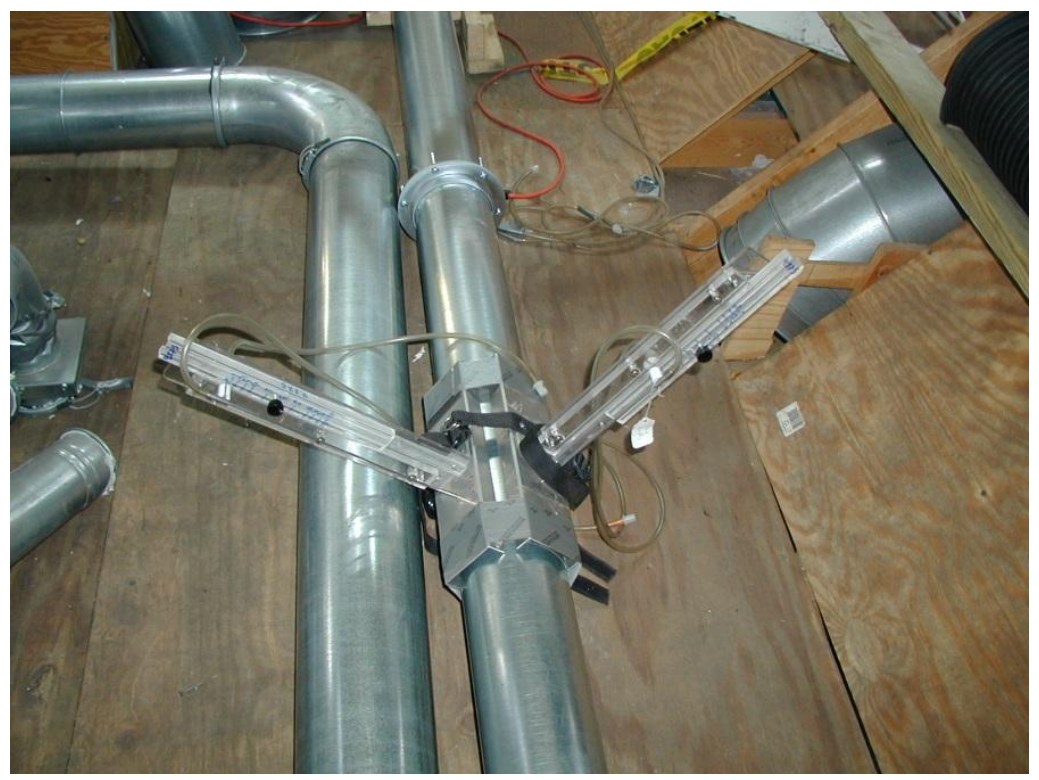

Figure 7 - Measurement Location

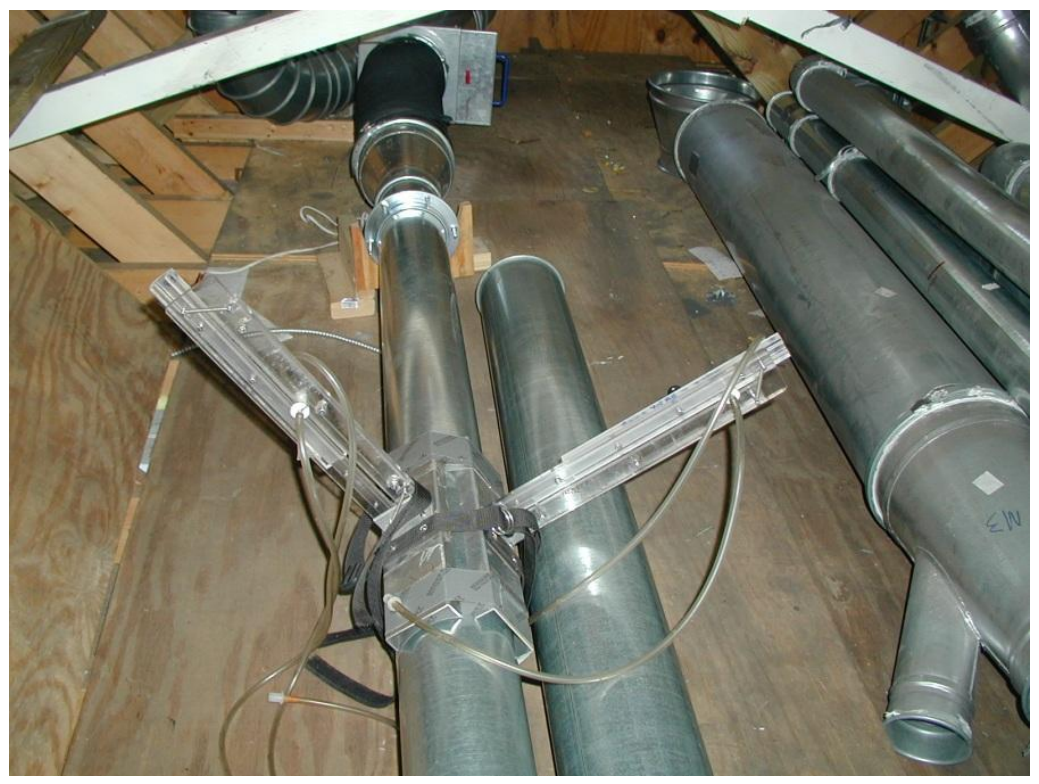

Figure 8 - Measurement Location and Slide-gate Damper

Calibration of the digital manometer was verified with a Dwyer No. 1425 hook gauge. Test values of $0,1 / 4,1 / 2,3 / 4,1,1 \frac{1}{2}, 2,3,4,5$, and 6 inch $\mathrm{H}_{2} \mathrm{O}$ were selected to correspond to the range of measured values.

The environmental conditions were evaluated as follows. The barometric pressure was recorded with a Princo (Southampton, PA) mercury barometer. Wet bulb and dry bulb temperatures were measured with an Industrial Instruments \& Supplies (Southampton, 
PA) model 22010 wet sock psychrometer, which made it possible to compute the moisture content.

\section{Data Acquisition}

Data was recorded using the HvMeasurement software written by Guffey (2008). The measured ambient barometric pressure as well as the dry bulb and wet bulb temperatures were manually entered into the program. Static pressure values were read from the PVM-100 by means of the serial port. The pressure values were printed to the serial port every 3 seconds and displayed in the HvMeasurement interface. Upon clicking the record button, the software would automatically enter the current (instantaneous) value into the spreadsheet and move the cursor to the next cell.

\section{Methods}

\section{Experimental}

The mean duct velocity was set by adjusting a slide-gate damper located between the test section and the fan inlet, until the centerline velocity pressure matched the velocity pressure associated to the target test velocity as listed in Table 3. The static and velocity pressures were measured using a pitot-static tube marked with the log-Tchebycheff traverse points and recorded with HvMeasurement, a data acquisition program written by Dr. Steven Guffey. The test conditions, target velocity, ambient barometric pressure, as well as the dry-bulb and wet-bulb temperatures were also recorded in the table. HvMeasurement also calculates the actual air flowrate, average velocity, Reynolds number, static pressure losses, f-factors, and equivalent roughness values based on the recorded data. This application was used solely for the purpose of simplifying the data collection process to record the test/target conditions, environmental data, and experimentally determined static/velocity pressure values.

For an individual test point, after adjusting the velocity at the damper the flow was allowed to stabilize for $5 \mathrm{~min}$ before making the pressure measurements. For a given pressure measurement, the display values were monitored and the mean value was acquired to HvMeasurement. Data was collected without replications as there were 10 
duct configurations and 8 test velocities for each configuration (total 80 test points) thus still allowing regression curves to be fitted to the data.

The raw data was imported into an Excel® sheet, in which the fluid flow parameters and pressure losses were calculated. The friction factor was calculated for the various predictor equations using hydraulically smooth conditions $(\mathrm{e}=0)$ at the Reynolds numbers from the experimental flow data. Back calculation using the Colebrook equation was performed to determine an appropriate roughness value for the data set. The friction factor was for this roughness value as well. Log-model linear regression was performed to develop predictor models for the $f$-value as well as the pressure loss per foot. Based on these values the predicted static pressure losses in the test section were computed. These values were compared to the experimental values for the mid-end region of the test section, as this region would show the least amount of entry effects and thus the best comparison, to determine which predictor equation would best approximate the observed pressure losses.

\section{Calculations}

The experimental procedure consisted of collecting the dry-bulb and wet bulb temperatures, barometric pressure, two 10-point (plus center line) log-Tchebycheff velocity pressure traverse, as well as hood, mid, and end static pressures. The remaining flow properties for each test condition were calculated as outlined in Appendix A.

To compute the hood entry loss factor at a given location, it is necessary to first compute the total pressure due to the hood throat for that location as given in Equation 12. Note: for suction the SP values are negative.

$$
T P_{h e}=S P+V P_{a v g}-S P_{f}=S P+V P_{a v g}-L\left(\frac{S P_{f}}{L_{r e f}}\right)
$$

Where:

$\mathrm{TP}_{\text {he }}=$ total pressure attributed to hood throat

$\mathrm{L}=$ Actual length

$\mathrm{L}_{\text {ref }}=$ Reference length

The hood entry loss factor is computed from Equation 13. 


$$
F_{h}=-\frac{T P_{h e}}{V P_{a v g}}
$$

Where:

$$
\mathrm{F}_{\mathrm{h}}=\text { hood entry loss factor }
$$

The more complex formulas (such as the humidity ratio and Colebrook equation, which require intermediate steps and/or iterations) were implemented in Excel@ by means of User Defined Functions (UDFs) given in Appendix B.

\section{Results \& Discussion}

The collected velocity pressure profiles were plotted to examine if the airflow profile is symmetrical and to allow examination of similarity at varying velocities. Figure 9 depicts the velocity pressure profiles for both Flanged and QUICK-FIT 8 inch ducts. These profiles were normalized by dividing the point VPs by $\mathrm{VP}_{\mathrm{avg}}$. The normalized profiles for the 8 inch duct are given in Figure 10. It can be seen that for most velocities the profiles for both duct types are very similar, while for some velocities there are marked differences. However, the normalized VP profiles appear to be almost identical for all velocities and duct types. This same behavior is apparent for all tested duct diameters. 


\section{Velocity profiles for nominal 8 inch duct}

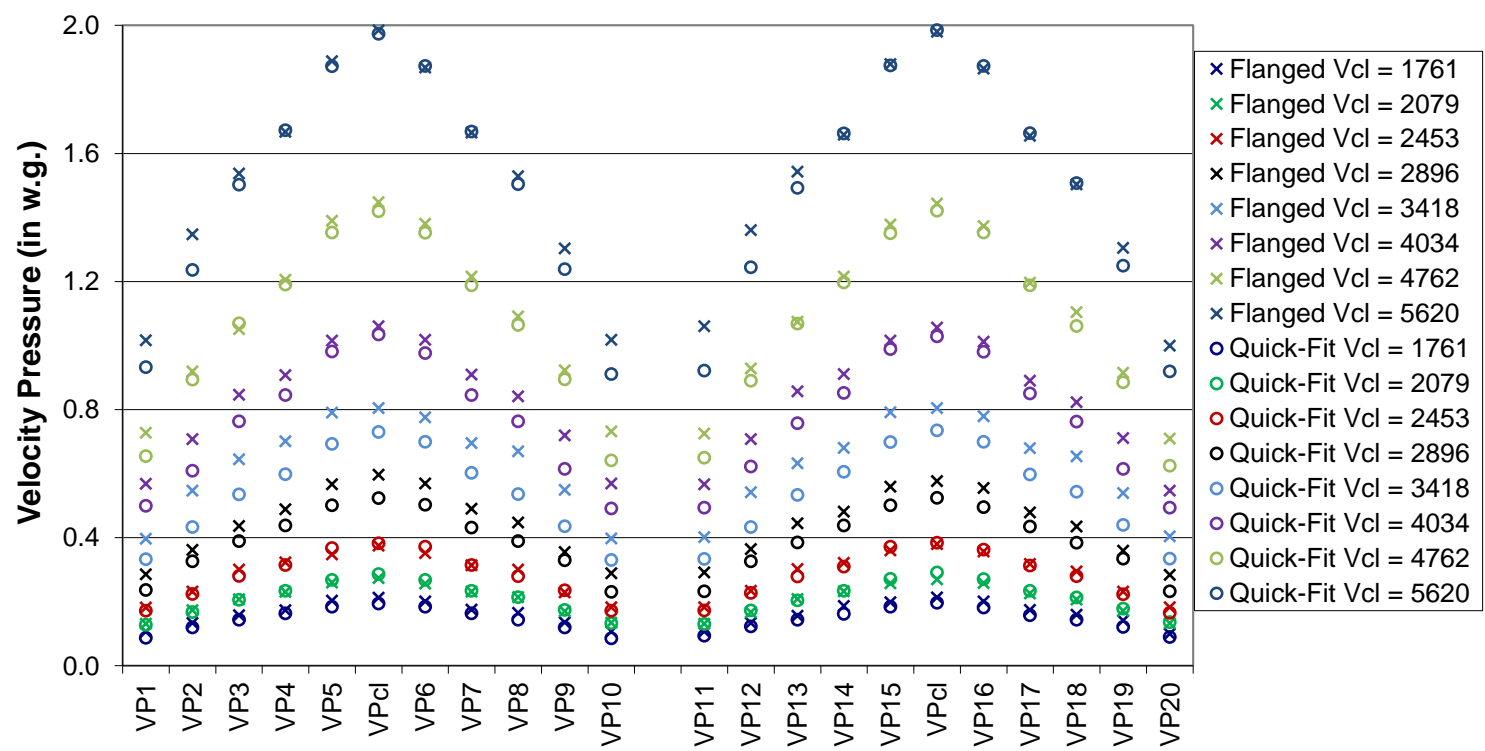

Traverse Point

Figure 9 - Velocity pressure profiles for 8" ducts

\section{Normalized velocity profiles for nominal 8 inch duct}

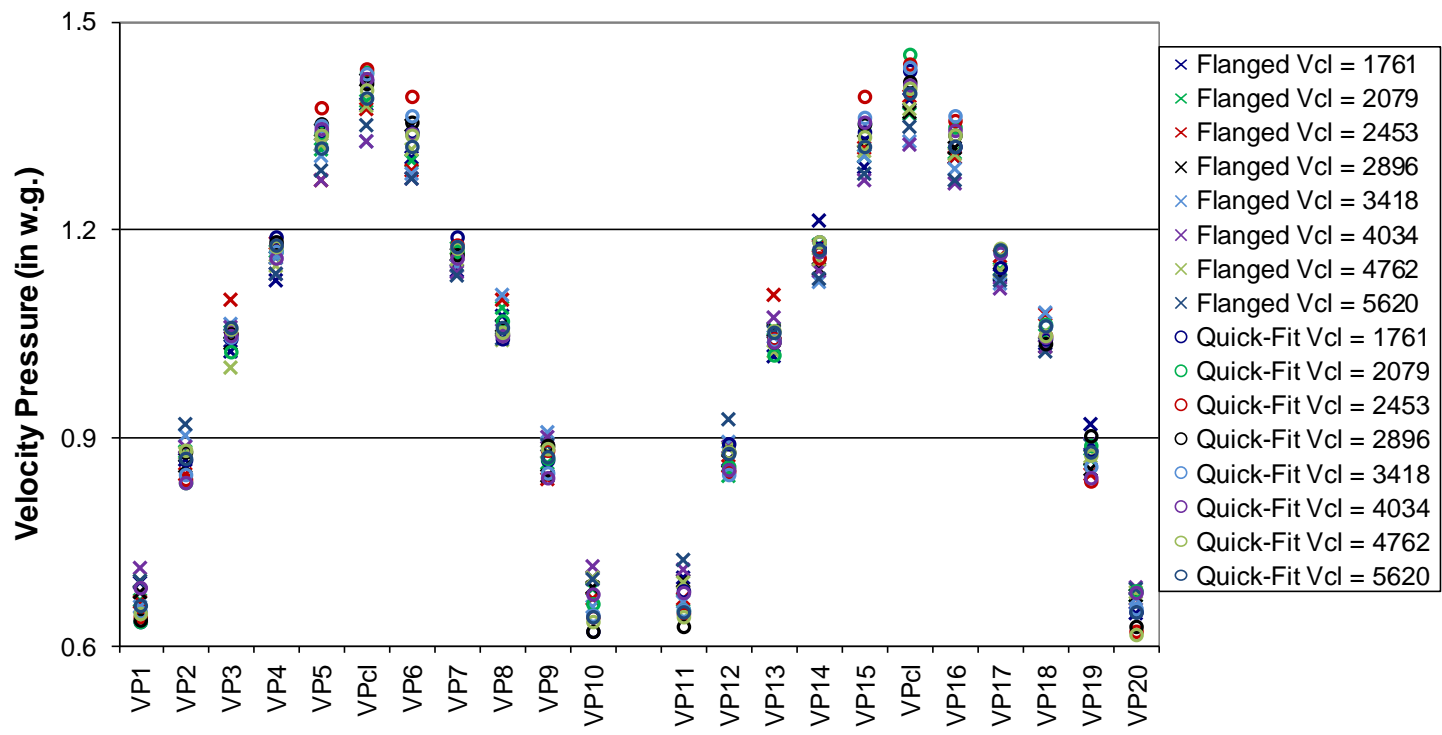

Traverse Point

Figure 10 - Velocity pressure profiles normalized by $\mathbf{V P}_{\text {avg }}$ 
Figure 11 shows the observed min-end pressure loss per foot for both the Flanged and Quick-Fit ducts. The curves are generally overlapping, indicating that there is no significant difference in losses between the two duct types.

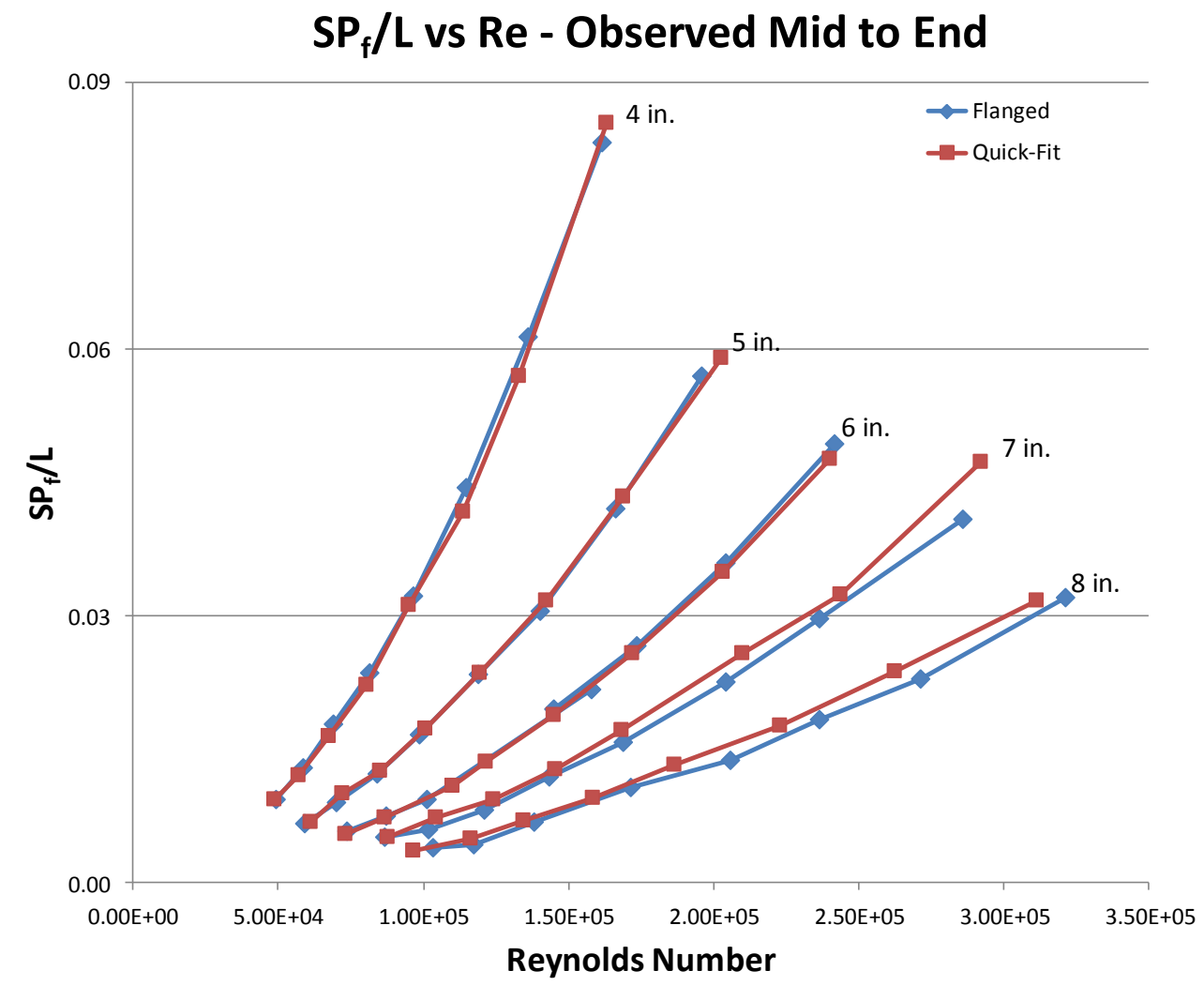

Figure 11 - Observed pressure losses for ME section

The condition presented in Equation 10 was applied to the observed flow data with $\varepsilon=5 \times 10^{-4} \mathrm{ft}$ (see Table 4). This indicates that for all tested cases hydraulically smooth conditions are applicable for $\varepsilon \leq 5 \times 10^{-4} \mathrm{ft}$. 
Table 4 - Idelchick equations for observed data

\begin{tabular}{|c|c|c|c|c|c|c|c|c|}
\hline \multirow{2}{*}{$\begin{array}{l}\text { Duct } \\
\text { Type }\end{array}$} & \multirow{2}{*}{$\begin{array}{l}\text { Nominal } \\
\text { duct Dia } \\
\text { (in) }\end{array}$} & \multirow[b]{2}{*}{$\mathrm{D}_{\mathrm{h}}(\mathrm{ft})$} & \multirow[b]{2}{*}{$\min R e$} & \multirow[b]{2}{*}{$\max R e$} & \multirow{2}{*}{$\frac{\varepsilon}{D_{h}}$} & \multicolumn{2}{|c|}{$\frac{181 \cdot \log (\operatorname{Re})-16.4}{\operatorname{Re}}$} & \multirow[b]{2}{*}{ Conditions } \\
\hline & & & & & & $\min$ & $\max$ & \\
\hline \multirow{5}{*}{$\begin{array}{l}\text { D } \\
\text { 은 } \\
\frac{\overline{0}}{4}\end{array}$} & 4 & 0.323 & 499256 & 161632 & 0.001548 & 0.01691 & 0.005731 & Smooth \\
\hline & 5 & 0.406 & 58910 & 196071 & 0.001231 & 0.014378 & 0.004802 & Smooth \\
\hline & 6 & 0.490 & 73757 & 241921 & 0.001021 & 0.011723 & 0.00396 & Smooth \\
\hline & 7 & 0.573 & 86873 & 286228 & 0.000873 & 0.010101 & 0.003393 & Smooth \\
\hline & 8 & 0.656 & 103611 & 321672 & 0.000762 & 0.008603 & 0.003048 & Smooth \\
\hline \multirow{5}{*}{ 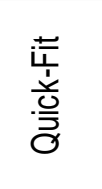 } & 4 & 0.323 & 48527 & 163006 & 0.001548 & 0.01714 & 0.005687 & Smooth \\
\hline & 5 & 0.406 & 61047 & 202542 & 0.001231 & 0.013921 & 0.004661 & Smooth \\
\hline & 6 & 0.490 & 72965 & 240423 & 0.001021 & 0.011839 & 0.003983 & Smooth \\
\hline & 7 & 0.573 & 87812 & 292528 & 0.000873 & 0.010003 & 0.003326 & Smooth \\
\hline & 8 & 0.656 & 96428 & 311592 & 0.000762 & 0.009186 & 0.003139 & Smooth \\
\hline
\end{tabular}

Figure 12 compares the observed and predicted hydraulically smooth pressure losses.

The Prandtl and Colebrook equations (with $\varepsilon=0$ ) predict the same $f$ value, which is identical to the value computed by the Nikuradse equation.

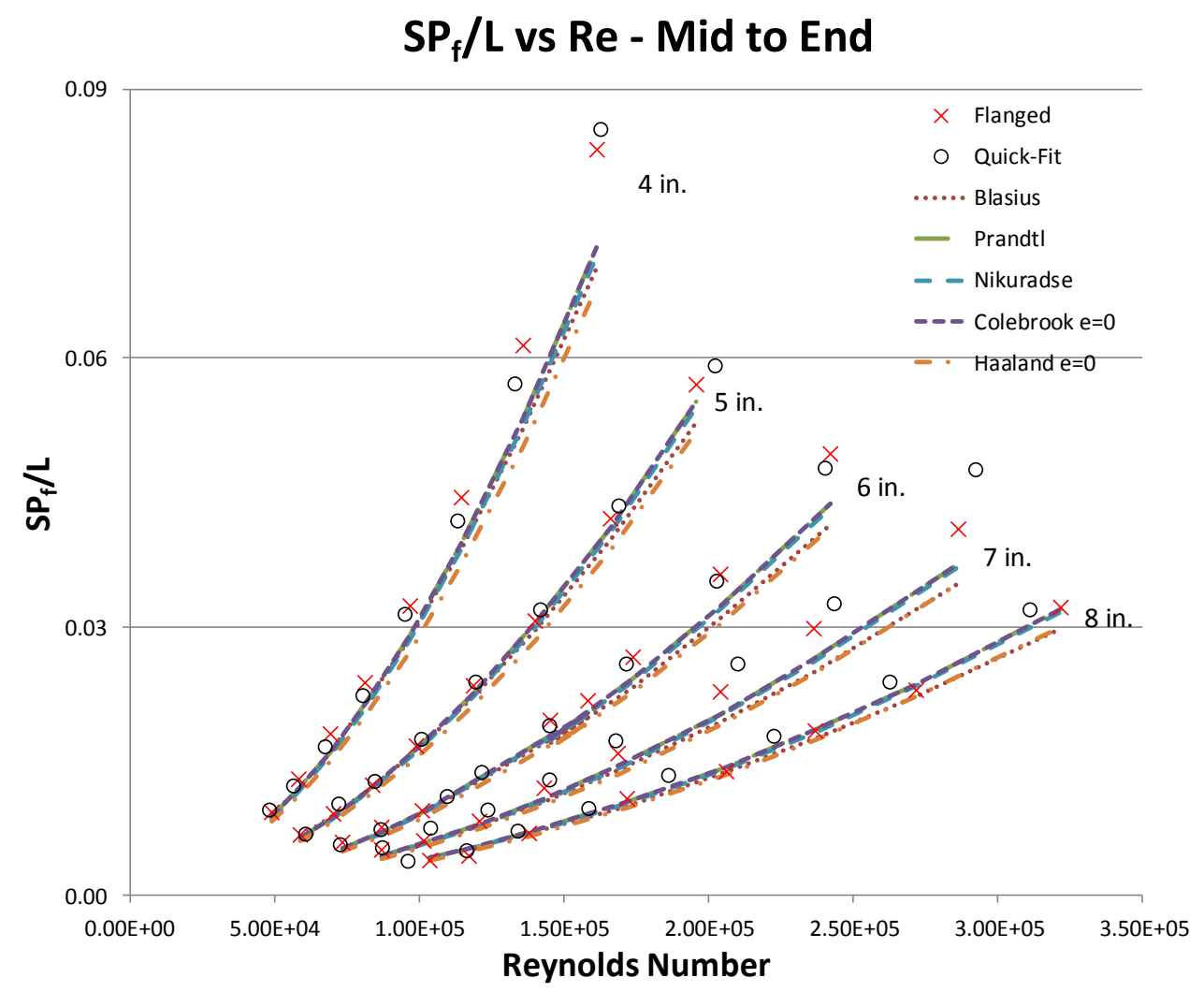

Figure 12 - Hydraulically smooth predictor comparisons 
Since all the hydraulically smooth predictors underestimated the pressure losses, the Colebrook equation was used to find $\varepsilon$ values such that $f_{\text {Colebrook }} \approx f_{\text {observed. Table } 5}$ presents the average roughness values at each diameter along with the mean for each duct type and overall mean. This indicates that applying the Colebrook equation with an $\varepsilon$ value between $1 \times 10^{-4} \mathrm{ft}$ and $1.6 \times 10^{-4} \mathrm{ft}$ should provide the best fit for the data.

Table 5 - Mean absolute roughness values for each nominal diameter tested

\begin{tabular}{|c|c|c|}
\hline \multirow{2}{*}{$\begin{array}{l}\text { Nominal } \\
\text { Diameter }\end{array}$} & \multicolumn{2}{|c|}{ Mean Absolute Roughness (ft) } \\
\hline & Flanged & Quick-fit \\
\hline 4 & $1.47 \mathrm{E}-04$ & $1.19 \mathrm{E}-04$ \\
\hline 5 & $3.53 \mathrm{E}-05$ & $9.13 \mathrm{E}-05$ \\
\hline 6 & $1.38 \mathrm{E}-04$ & $1.12 \mathrm{E}-04$ \\
\hline 7 & $1.61 \mathrm{E}-04$ & $4.27 \mathrm{E}-04$ \\
\hline 8 & $9.00 \mathrm{E}-06$ & $3.56 \mathrm{E}-05$ \\
\hline Mean & $9.81 \mathrm{E}-05$ & $1.57 \mathrm{E}-04$ \\
\hline Overall Mean & \multicolumn{2}{|c|}{$1.28 \mathrm{E}-04$} \\
\hline
\end{tabular}

Since McLoone et al. (1993) observed that entry effects can still be present $20 \mathrm{D}$ from the inlet, the mid-end region (40+ D from the inlet) was selected to analyze the friction losses. The log of static pressure loss per foot was plotted against the log of Re seen in Figure 13. The highly apparent linearity suggests that the friction loss was related to the velocity. The distinct lines for each diameter indicate that the loss per foot and thus the $f$ value would be dependent not only on velocity but also the diameter. Accordingly, a logmodel regression for the $f$-value was performed for each duct type. Two models were selected for comparison; namely one for all diameters (Equation 14) and one for a specified diameter (Equation 14 with $\mathrm{C}_{\mathrm{D}}=0$ ). The log model was converted to an exponential model given by Equations 15. The resulting regression coefficients are given in Table 6. 


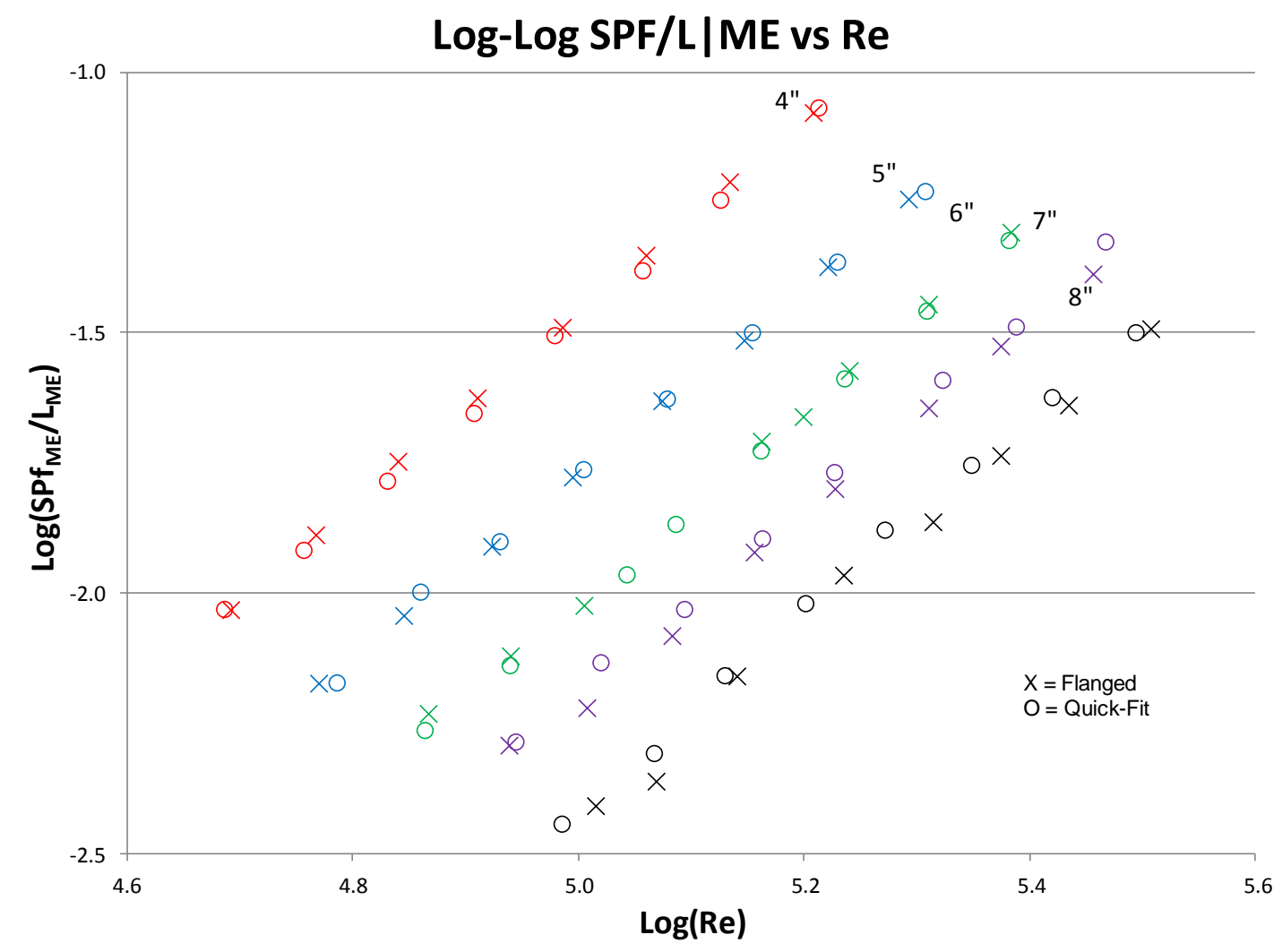

Figure 13 - Log-Log $\mathrm{SPf}_{\mathrm{ME}} / \mathrm{L}_{\mathrm{ME}}$ vs Re

$$
\begin{aligned}
& \log (f)=C_{0}+C_{V e l} \log \left(\mathrm{V}_{a v g}\right)+C_{D} \log \left(D_{h}\right) \\
& f=10^{C_{0}} \mathrm{~V}_{\text {avg }}{ }^{C_{V e l}} D_{h}{ }^{C_{D}}
\end{aligned}
$$

\begin{tabular}{|c|c|c|c|c|c|c|c|c|c|c|c|c|}
\hline \multirow[b]{2}{*}{$\begin{array}{c}\text { Nominal } \\
\text { Dia }\end{array}$} & \multicolumn{4}{|c|}{ Flanged } & \multicolumn{4}{|c|}{ Quick-Fit } & \multicolumn{4}{|c|}{ All } \\
\hline & $\mathrm{C}_{0}$ & $\mathrm{C}_{\mathrm{Vel}}$ & $C_{D}$ & $\mathrm{R}^{2}$ & $\mathrm{C}_{0}$ & $\mathrm{C}_{\mathrm{Vel}}$ & $C_{D}$ & $\mathrm{R}^{2}$ & $\mathrm{C}_{0}$ & $\mathrm{C}_{\mathrm{Vel}}$ & $C_{D}$ & $\mathrm{R}^{2}$ \\
\hline 4 & -1.158 & -0.154 & & $97.3 \%$ & -1.108 & -0.171 & & $87.4 \%$ & 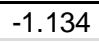 & -0.162 & & $89.8 \%$ \\
\hline 5 & -1.009 & -0.213 & & $98.2 \%$ & -1.002 & -0.211 & & $90.7 \%$ & -1.005 & -0.212 & & $91.3 \%$ \\
\hline 6 & -1.108 & -0.182 & & $84.3 \%$ & -1.182 & -0.162 & & $91.4 \%$ & -1.147 & -0.171 & & $87.1 \%$ \\
\hline 7 & -1.111 & -0.184 & & $75.6 \%$ & -1.101 & -0.173 & & $86.8 \%$ & -1.098 & -0.181 & & $51.9 \%$ \\
\hline 8 & -1.442 & -0.108 & & $27.2 \%$ & -1.378 & -0.119 & & $60.4 \%$ & -1.400 & -0.116 & & $37.6 \%$ \\
\hline All & -0.914 & -0.172 & -0.316 & $77.1 \%$ & \begin{tabular}{|l|l|}
-0.997 \\
\end{tabular} & -0.172 & -0.186 & $57.6 \%$ & -0.951 & -0.173 & -0.251 & $65.8 \%$ \\
\hline
\end{tabular}

Table 6 - Regression coefficients for $f$-value log predictor model

The $\mathrm{R}^{2}$ value became progressively lower with increasing diameter. This indicates that a regression model for the $f$-value may not be the ideal choice. Accordingly, a regression model was selected to directly predict the pressure loss per foot. The revised log regression model and exponential form are given in Equations 16 and 17 respectively. 
Table 7 shows the regression coefficients and $\mathrm{R}^{2}$ values for this revised model. Since $\mathrm{R}^{2} \geq 98.8 \%$ for all cases indicates that the log model for pressure loss per foot fits the data much better. Since all $\mathrm{R}^{2}$ values are essentially the same, the best fitted predictor equation (of pressure loss per foot) that was selected for comparison with other predictors is given in Equation 18. To check the validity of the assumption that the log model for pressure loss per foot was better than the log model for the $f$-value (due to the higher $\mathrm{R}^{2}$ value), comparisons were also made to the predicted $\mathrm{SP}_{\mathrm{f}} / \mathrm{L}$ computed from the $f$-value $\log$ models for specified diameter and specified diameter \& type outlined in Table 6.

$$
\begin{aligned}
& \log \left(S P_{f} \text { per foot }\right)=C_{0}+C_{V e l} \log \left(\mathrm{V}_{a v g}\right)+C_{D} \log \left(D_{h}\right) \\
& S P_{f} \text { per foot }=10^{C_{0}} \mathrm{~V}_{\text {avg }}{ }^{C_{\text {Vel }}} D_{h}{ }^{C_{D}}
\end{aligned}
$$

\begin{tabular}{|c|c|c|c|c|c|c|c|c|c|c|c|c|}
\hline \multirow[b]{2}{*}{$\begin{array}{c}\text { Nominal } \\
\text { Dia }\end{array}$} & \multicolumn{4}{|c|}{ Flanged } & \multicolumn{4}{|c|}{ Quick-Fit } & \multicolumn{4}{|c|}{ All } \\
\hline & $\mathrm{C}_{0}$ & $\mathrm{C}_{\mathrm{Vel}}$ & $C_{D}$ & $\mathrm{R}^{2}$ & $\mathrm{C}_{0}$ & $\mathrm{C}_{\mathrm{Vel}}$ & $\mathrm{C}_{\mathrm{D}}$ & $\mathrm{R}^{2}$ & $\mathrm{C}_{0}$ & $\mathrm{C}_{\mathrm{Vel}}$ & $\mathrm{C}_{\mathrm{D}}$ & $\mathrm{R}^{2}$ \\
\hline 4 & "-7.920 & 1.857 & & $100.0 \%$ & "-7.878 & 1.842 & & $99.9 \%$ & -7.900 & 1.850 & & $99.9 \%$ \\
\hline 5 & -7.870 & 1.794 & & $100.0 \%$ & -7.853 & 1.794 & & $99.8 \%$ & -7.861 & 1.794 & & $99.8 \%$ \\
\hline 6 & -8.049 & 1.828 & & $99.8 \%$ & -8.120 & 1.847 & & $99.9 \%$ & -8.086 & 1.838 & & $99.9 \%$ \\
\hline 7 & -8.109 & 1.822 & & $99.7 \%$ & -8.087 & 1.832 & & $99.9 \%$ & -8.088 & 1.824 & & $98.9 \%$ \\
\hline 8 & -8.509 & 1.899 & & $99.4 \%$ & -8.449 & 1.887 & & $99.8 \%$ & -8.471 & 1.891 & & $99.5 \%$ \\
\hline All & -7.065 & 1.836 & -1.339 & $99.3 \%$ & -7.138 & 1.834 & -1.215 & $98.8 \%$ & -7.097 & 1.834 & -1.277 & $99.0 \%$ \\
\hline
\end{tabular}

Table 7 - Regression coefficients for pressure loss per foot log predictor model

$$
S P_{f} \text { per foot }=10^{-7.097} \mathrm{~V}_{\text {avg }}{ }^{1.834} D_{h}^{-1.277}
$$

The observed pressure losses were plotted along with those predicted from the selected regression models as well as the Haaland equation and the Colebrook equation for $\varepsilon=1 \times 10^{-4} \mathrm{ft}$. Figure 14 shows the observed and predicted pressure loss. By visual inspection it can be seen that the Haaland equation consistently underestimates the $f$ value and consequently the pressure loss. Also, the log model for predicted pressure loss per foot predicted nearly the same values as the Colebrook equation. The interesting point is that although the $\mathrm{R}^{2}$ for the $f$-value log models was low, they yielded the best fit for the pressure loss per foot. The $f$-value model for specified diameter and type almost perfectly followed the observed values. 


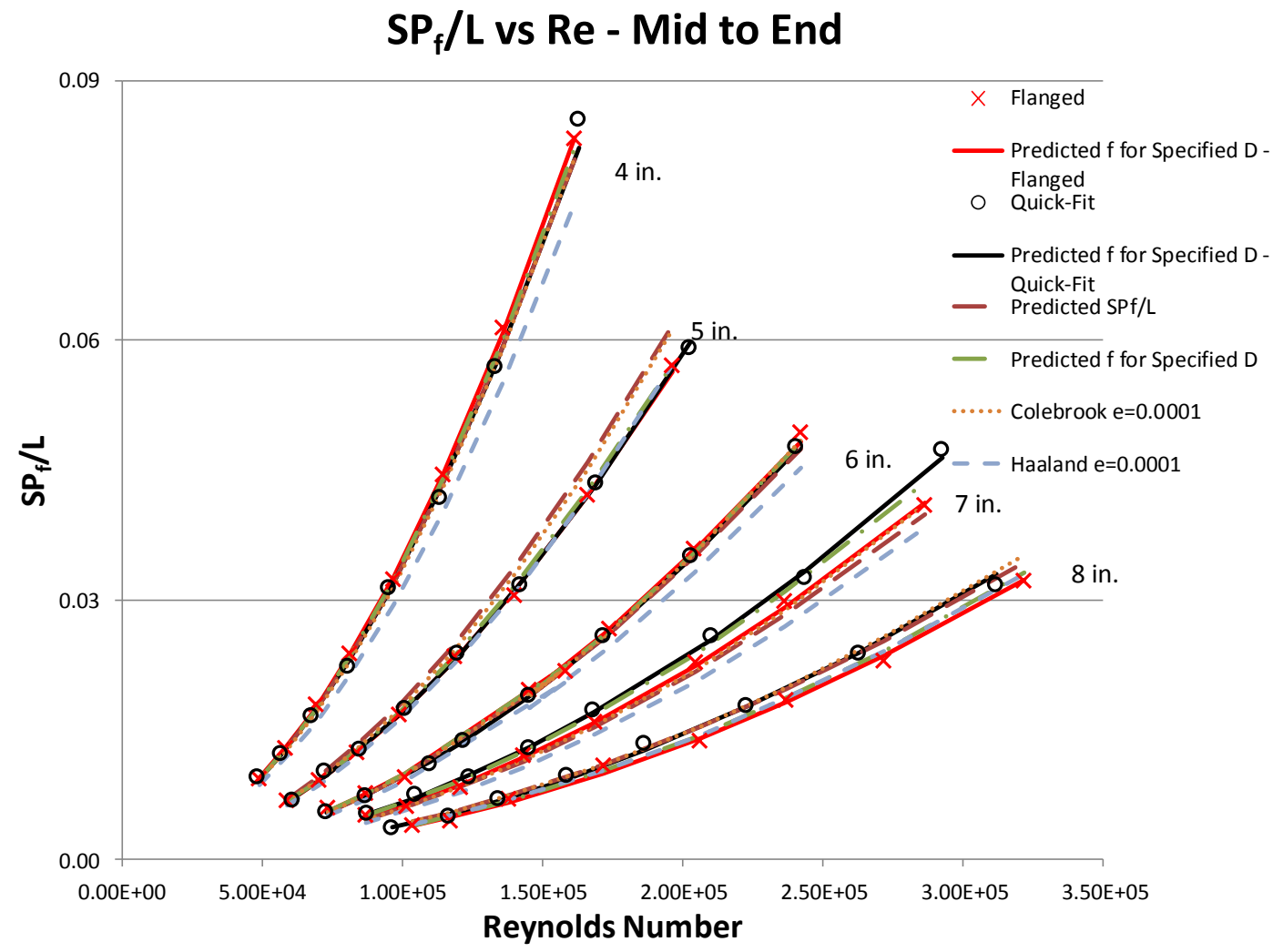

Figure 14 - Pressure loss per $\mathrm{ft}$ vs Re for mid-end region

The data in Table 8 shows that predictor models for hydraulically smooth conditions predicted lower losses than the observed values. The values predicted by the Prandtl equation as well as the Colebrook equation with $\varepsilon=0$ feet (best fit to the observed) both underestimated the pressure loss by about $6 \%$. The values predicted by the Haaland equation with $\varepsilon=0.0001$ feet were nearly the same as the predictions of the hydraulically smooth models. The Colebrook equation with $\varepsilon=0.0001$ feet, the $f$-value log model with specified duct diameter, and log model for pressure loss per foot on average predicted losses within $2 \%$ of the observed; though the $f$-value log model with specified duct diameter had less deviation from the observed values. The $f$-value log model for specified type and diameter was on average within $0.04 \%$ of the observed with the least deviation.

Table 9 shows that over the Mid-End region all the errors (apparent in Figure 14) for the hydraulically smooth predictor models and the Haaland model with $\varepsilon=0.0001$ feet were within $-0.3 /+0.02$ in w.g. of the observed values with an average error of about - 
0.05 in w.g. The $\log$ models and Colebrook equation with $\varepsilon=0.0001$ feet predicted values within $-0.14 /+0.8$ in w.g. of the observed values with no mean error. The range in errors is most likely due to the turbulent nature of the flow as the pressure values displayed on the PVM-100 fluctuated by as much as 0.2 in $\mathrm{H}_{2} \mathrm{O}$, particularly at higher duct velocities.

Table 8 - \% Error in predicted $\mathrm{SP}_{\mathrm{f}} / \mathrm{L}$ over the mid-end region

\begin{tabular}{|c|c|c|c|c|c|c|c|c|c|c|c|}
\hline & & \multicolumn{10}{|c|}{$\%$ Error SPF/L for Mid-End region } \\
\hline & & \multicolumn{3}{|c|}{ Log Models } & \multicolumn{5}{|c|}{ Hydraulically Smooth $(\varepsilon=0)$} & \multicolumn{2}{|c|}{$\varepsilon=0.0001$} \\
\hline & & $\begin{array}{l}\text { Predicted } \\
\mathrm{SP}_{\mathrm{f}} / \mathrm{L}\end{array}$ & $\begin{array}{l}\text { Predicted } \\
f \text { for } \\
\text { specified } \\
\text { Dia and } \\
\text { Type }\end{array}$ & $\begin{array}{l}\text { Predicted } \\
f \text { for } \\
\text { specified } \\
\text { Dia }\end{array}$ & Blasius & Prandtl & Nikuradse & Colebrook & Haaland & Colebrook & Haaland \\
\hline \multirow{3}{*}{ Minimum } & All & $-18.73 \%$ & $-8.17 \%$ & $-8.68 \%$ & $-27.06 \%$ & $-22.08 \%$ & $-22.84 \%$ & $-22.09 \%$ & $-26.84 \%$ & $-17.25 \%$ & $-22.77 \%$ \\
\hline & Flanged & $-10.57 \%$ & $-8.17 \%$ & $-5.51 \%$ & $-16.20 \%$ & $-14.12 \%$ & $-16.01 \%$ & $-14.13 \%$ & $-19.45 \%$ & $-10.29 \%$ & $-16.27 \%$ \\
\hline & Quick-Fit & $-18.73 \%$ & $-5.22 \%$ & $-8.68 \%$ & $-27.06 \%$ & $-22.08 \%$ & $-22.84 \%$ & $-22.09 \%$ & $-26.84 \%$ & $-17.25 \%$ & $-22.77 \%$ \\
\hline \multirow{3}{*}{ Maximum } & All & $25.57 \%$ & $10.79 \%$ & $14.39 \%$ & $17.57 \%$ & $19.70 \%$ & $17.58 \%$ & $19.68 \%$ & $12.27 \%$ & $25.58 \%$ & $17.21 \%$ \\
\hline & Flanged & $25.57 \%$ & $10.79 \%$ & $14.39 \%$ & $17.57 \%$ & $19.70 \%$ & $17.58 \%$ & $19.68 \%$ & $12.27 \%$ & $25.58 \%$ & $17.21 \%$ \\
\hline & Quick-Fit & $13.91 \%$ & $5.43 \%$ & $4.82 \%$ & $5.59 \%$ & $7.48 \%$ & $5.57 \%$ & $7.46 \%$ & $0.81 \%$ & $12.73 \%$ & $5.22 \%$ \\
\hline \multirow{3}{*}{ Average } & All & $0.30 \%$ & $0.04 \%$ & $0.08 \%$ & $-9.05 \%$ & $-6.82 \%$ & $-8.45 \%$ & $-6.83 \%$ & $-12.58 \%$ & $0.08 \%$ & $-6.55 \%$ \\
\hline & Flanged & $2.05 \%$ & $0.04 \%$ & $1.75 \%$ & $-7.58 \%$ & $-5.27 \%$ & $-6.92 \%$ & $-5.28 \%$ & $-11.12 \%$ & $1.77 \%$ & $-4.97 \%$ \\
\hline & Quick-Fit & $-1.45 \%$ & $0.04 \%$ & $-1.58 \%$ & $-10.52 \%$ & $-8.37 \%$ & $-9.99 \%$ & $-8.39 \%$ & $-14.04 \%$ & $-1.61 \%$ & $-8.13 \%$ \\
\hline \multirow{3}{*}{ STD Dev } & All & $7.62 \%$ & $2.88 \%$ & $4.14 \%$ & $7.02 \%$ & $6.79 \%$ & $6.66 \%$ & $6.78 \%$ & $6.36 \%$ & $7.00 \%$ & "6.54\% \\
\hline & Flanged & $6.84 \%$ & $3.24 \%$ & $4.16 \%$ & $6.66 \%$ & $6.61 \%$ & $6.55 \%$ & $6.61 \%$ & $6.20 \%$ & $6.72 \%$ & $6.28 \%$ \\
\hline & Quick-Fit & $8.04 \%$ & $2.51 \%$ & $3.43 \%$ & $7.14 \%$ & $6.68 \%$ & $6.50 \%$ & $6.68 \%$ & $6.27 \%$ & $6.96 \%$ & $6.50 \%$ \\
\hline
\end{tabular}

Table 9 - Error (in H2O) for Mid-End region

\begin{tabular}{|c|c|c|c|c|c|c|c|c|c|c|c|}
\hline & & \multicolumn{10}{|c|}{ Error (inch w.g.) SPF/L for Mid-End region } \\
\hline & & \multicolumn{3}{|c|}{ Log Models } & \multicolumn{5}{|c|}{ Hydraulically Smooth $(\varepsilon=0)$} & \multicolumn{2}{|c|}{$\varepsilon=0.0001$} \\
\hline & & $\begin{array}{l}\text { Predicted } \\
\mathrm{SP}_{\mathrm{f}} / \mathrm{L}\end{array}$ & \begin{tabular}{|l} 
Predicted \\
$f$ for \\
specified \\
Dia and \\
Type \\
\end{tabular} & $\begin{array}{l}\text { Predicted } \\
f \text { for } \\
\text { specified } \\
\text { Dia }\end{array}$ & Blasius & Prandtl & Nikuradse & Colebrook & Haaland & Colebrook & Haaland \\
\hline \multirow{3}{*}{ Minimum } & All & -0.155 & -0.059 & -0.070 & -0.267 & -0.222 & -0.241 & -0.222 & -0.307 & -0.122 & -0.172 \\
\hline & Flanged & -0.047 & -0.019 & -0.024 & -0.253 & -0.207 & -0.227 & -0.207 & -0.294 & -0.045 & -0.144 \\
\hline & Quick-Fit & -0.155 & -0.059 & -0.070 & -0.267 & -0.222 & -0.241 & -0.222 & -0.307 & -0.122 & -0.172 \\
\hline \multirow{3}{*}{ Maximum } & All & 0.091 & 0.023 & 0.052 & 0.015 & 0.017 & 0.015 & 0.017 & 0.010 & 0.083 & 0.022 \\
\hline & Flanged & 0.091 & 0.013 & 0.052 & 0.015 & 0.017 & 0.015 & 0.017 & 0.010 & 0.083 & 0.022 \\
\hline & Quick-Fit & 0.071 & 0.023 & 0.031 & 0.005 & 0.007 & 0.005 & 0.007 & 0.001 & 0.068 & 0.005 \\
\hline \multirow{3}{*}{ Average } & All & -0.001 & 0.000 & -0.001 & -0.049 & -0.036 & -0.042 & -0.036 & -0.061 & -0.001 & -0.029 \\
\hline & Flanged & 0.005 & 0.000 & 0.004 & -0.045 & -0.032 & -0.038 & -0.032 & -0.057 & 0.005 & -0.025 \\
\hline & Quick-Fit & -0.007 & 0.000 & -0.006 & -0.053 & -0.041 & -0.047 & -0.041 & -0.065 & -0.006 & -0.034 \\
\hline
\end{tabular}

The average error in $\mathrm{SP}_{\mathrm{f}}$ vs. target velocity for the Mid-End region is given in Table 10 . This shows that the hydraulically smooth predictor models will increasingly underestimate pressure losses with higher velocities (as much as 15\% at 5058 FPM). The Haaland equation with $\varepsilon=0.0001$ feet showed a similar trend as the hydraulically smooth predictors, yet was not as significantly affected by velocity. The log models and the 
Colebrook equation with $\varepsilon=0.0001$ feet followed the data much better with no significant mean error regardless of duct velocity.

Table 10 - Average Error of $S_{P_{f}}$ vs Target $V_{\text {avg }}$ for the Mid-End Region

\begin{tabular}{|c|c|c|c|c|c|c|c|c|c|c|}
\hline \multirow[b]{3}{*}{$\begin{array}{l}\text { Target } \\
\mathrm{V}_{\text {avg }} \\
\text { (FPM) }\end{array}$} & \multicolumn{10}{|c|}{ Error (inch w.g.) SPF/L for Mid-End region } \\
\hline & \multicolumn{3}{|c|}{ Log Models } & \multicolumn{5}{|c|}{ Hydraulically Smooth $(\varepsilon=0)$} & \multicolumn{2}{|c|}{$\varepsilon=0.0001$} \\
\hline & $\begin{array}{l}\text { Predicted } \\
\mathrm{SP}_{\mathrm{f}} / \mathrm{L}\end{array}$ & $\begin{array}{l}\text { Predicted } \\
f \text { for } \\
\text { specified } \\
\text { Dia and } \\
\text { Type }\end{array}$ & $\begin{array}{l}\text { Predicted } \\
f \text { for } \\
\text { specified } \\
\text { Dia }\end{array}$ & Blasius & Prandtl & Nikuradse & Colebrook & Haaland & Colebrook & Haaland \\
\hline 1585 & -0.009 & -0.014 & -0.014 & -0.059 & -0.059 & -0.084 & -0.060 & -0.118 & -0.016 & -0.081 \\
\hline 1871 & 0.021 & 0.014 & 0.015 & -0.043 & -0.038 & -0.060 & -0.038 & -0.097 & 0.012 & -0.055 \\
\hline 2208 & 0.017 & 0.014 & 0.014 & -0.060 & -0.049 & -0.068 & -0.049 & -0.108 & 0.008 & -0.059 \\
\hline 2606 & -0.002 & -0.004 & -0.004 & -0.091 & -0.073 & -0.089 & -0.073 & -0.130 & -0.009 & -0.075 \\
\hline 3076 & -0.004 & -0.007 & -0.007 & -0.104 & -0.080 & -0.094 & -0.080 & -0.137 & -0.009 & -0.075 \\
\hline 3631 & 0.004 & 0.002 & 0.002 & -0.109 & -0.077 & -0.090 & -0.077 & -0.134 & 0.003 & -0.063 \\
\hline 4285 & 0.002 & 0.003 & 0.002 & -0.120 & -0.081 & -0.092 & -0.081 & -0.137 & 0.008 & -0.058 \\
\hline 5058 & -0.005 & -0.003 & -0.003 & -0.138 & -0.090 & -0.100 & -0.090 & -0.146 & 0.009 & -0.056 \\
\hline
\end{tabular}

The entry loss factor $\left(\mathrm{F}_{\mathrm{h}}\right)$ values were computed for each test condition using Equation 13. It was found that for each duct type and diameter the $\mathrm{F}_{\mathrm{h}}$ value varied less than $3 \%$ across the tested velocity range. The mean $F_{h}$ values are listed in Table 11. The table shows that the $F_{h}$ values at the mid and end locations are the same. This indicates that entry effects seen at the hood measurement point apparently have dissipated by the mid location. A negative $F_{h}$ value was determined for all test locations in the 4 inch Flanged duct, as well as in the hood location of the 8 inch Flanged and 5 inch Quick-Fit ducts. This could have been due to possible leaks in the joints between the initial duct sections (that were suspended from cables).

Table 11 - Mean $F_{h}$ values for duct type and diameter determined at hood, mid, and end measurement locations

\begin{tabular}{|c|c|c|c|c|c|c|}
\hline & \multicolumn{3}{|c|}{ Flanged } & \multicolumn{3}{c|}{ Quick-Fit } \\
\hline Dia & Hood & Mid & End & Hood & Mid & End \\
\hline \hline 4 & -0.314 & -0.186 & -0.186 & 0.249 & 0.154 & 0.154 \\
\hline 5 & 0.186 & 0.168 & 0.168 & -0.558 & 0.286 & 0.286 \\
\hline 6 & 0.145 & 0.142 & 0.142 & 0.266 & 0.407 & 0.407 \\
\hline 7 & 0.104 & 0.203 & 0.203 & 0.298 & 0.179 & 0.179 \\
\hline 8 & -0.064 & 0.270 & 0.270 & 0.442 & 0.482 & 0.482 \\
\hline Mean & 0.011 & 0.119 & 0.119 & 0.140 & 0.302 & 0.302 \\
\hline
\end{tabular}




\section{Experimental Uncertainty}

It is desirable to estimate the magnitude of possible error (uncertainty) in computed experimental values. This is inherently dependent upon the uncertainty of the individual measurements used to calculate a given parameter. Moffat (1988) suggested that the uncertainty in the result can be expressed in terms of the individual measurement uncertainties by Equation 19.

$$
\Delta R=\left\{\sum_{i=1}^{N}\left(\frac{\partial R}{\partial X_{i}} \Delta X_{i}\right)^{2}\right\}^{1 / 2}
$$

Where:

$$
\begin{aligned}
X_{i} & =i \text {-th measurement (or independent variable) } \\
R & =\text { Result as } f\left(X_{1}, X_{2}, \ldots, X_{N}\right) \\
\Delta R & =\text { Uncertainty of the computed result } \\
\Delta X_{i} & =\text { Uncertainty of } i \text {-th measurement (or independent variable) }
\end{aligned}
$$

Pressure values within the range of interest were measured with the PVM-100 and

\begin{tabular}{|c|c|c|c|}
\hline \multicolumn{3}{|c|}{ Pressure (in w.g.) } & \multirow{2}{*}{$\%$ Error } \\
\hline Reference & Measured & Error & \\
\hline 0.00 & 0.000 & 0.000 & \\
\hline-0.25 & -0.236 & 0.014 & $-5.60 \%$ \\
\hline-0.50 & -0.496 & 0.004 & $-0.80 \%$ \\
\hline-0.75 & -0.739 & 0.011 & $-1.47 \%$ \\
\hline-1.00 & -0.995 & 0.005 & $-0.50 \%$ \\
\hline-1.50 & -1.482 & 0.018 & $-1.20 \%$ \\
\hline-2.00 & -1.971 & 0.029 & $-1.45 \%$ \\
\hline-3.00 & -2.946 & 0.054 & $-1.80 \%$ \\
\hline-4.00 & -3.957 & 0.043 & $-1.08 \%$ \\
\hline-5.00 & -4.937 & 0.063 & $-1.26 \%$ \\
\hline \multirow[t]{2}{*}{-6.00} & -5.925 & 0.075 & $-1.25 \%$ \\
\hline & Average & 0.029 & $-1.64 \%$ \\
\hline
\end{tabular}
compared to the reference value set on the Dwyer 1425 hook gauge (see Table 12). This data shows that the measured values were generally within $1.64 \%$ of the reference value, which is fairly close to the manufacturer specified accuracy.

Table 12 - 26-Aug-2008 Calibration check of PVM-100

The uncertainties for the individual pressure measurements were evaluated as the highest error within the range of measured pressures. Temperature measurements were made 
using glass mercury thermometers (in a wet sock psychrometer) with an accuracy of $0.5^{\circ} \mathrm{F}$. Diameters were measured using a digital caliper with 0.001 inch precision. The length measurements were assumed to have an uncertainty of 0.5 inch. The mercury barometer scale had a precision of $0.05 \mathrm{mmHg}$. The uncertainties of the actual measurements are given in Table 13.

Table 13 - Uncertainties of measured values

\begin{tabular}{|l|c|c|c|}
\hline Measurement & Max value & Uncertainty & Units \\
\hline \hline SPh & 2.3 & 0.041 & in w.g. \\
\hline SPmid & 3.9 & 0.054 & in w.g. \\
\hline SPend & 5.5 & 0.069 & in w.g. \\
\hline VP1, VP10, VP11, VP20 & 1.2 & 0.015 & in w.g. \\
\hline VP2, VP9, VP12, VP19 & 1.4 & 0.018 & in w.g. \\
\hline VP3, VP8, VP13, VP18 & 1.6 & 0.020 & in w.g. \\
\hline VP4, VP7, VP14, VP17 & 1.7 & 0.025 & in w.g. \\
\hline VP5, VP6, VP15, VP16 & 2.0 & 0.029 & in w.g. \\
\hline Tdb, Twb & -- & 0.5 & 'F \\
\hline Dia & -- & 0.001 & in \\
\hline Lh, Lmid, Lend & -- & 0.5 & in \\
\hline Pbar & -- & 0.05 & $\mathrm{mmHg}$ \\
\hline
\end{tabular}

The uncertainties were computed for the reference case with the highest measured pressures, i.e. the case with the highest uncertainty. The selected case was the 4 in Quick-Fit with a test velocity of $4871 \mathrm{ft} / \mathrm{min}$. These uncertainties and percent of computed result are given in Table 14. It can be seen that there is less than $6 \%$ uncertainty in the computed pressure losses and $f$-values. 
Table 14 - Uncertainties for computed results

\begin{tabular}{|c|c|c|c|}
\hline Variable & Units & $\begin{array}{c}\text { Uncertainty } \\
(\Delta \mathrm{R})\end{array}$ & $\begin{array}{c}\text { Percent } \\
\text { Uncertainty }\end{array}$ \\
\hline \hline w & & $1.96 \mathrm{E}-04$ & $1.74 \%$ \\
\hline Qact & CFM & $7.11 \mathrm{E}-01$ & $0.18 \%$ \\
\hline Vavg & FPM & $8.31 \mathrm{E}+00$ & $0.17 \%$ \\
\hline Re & & $3.27 \mathrm{E}+02$ & $0.19 \%$ \\
\hline Lhm & $\mathrm{ft}$ & $5.89 \mathrm{E}-03$ & $0.03 \%$ \\
\hline Lme & $\mathrm{ft}$ & $5.89 \mathrm{E}-03$ & $0.03 \%$ \\
\hline Lhe & $\mathrm{ft}$ & $5.89 \mathrm{E}-03$ & $0.01 \%$ \\
\hline SPFhm & in w.g. & $6.78 \mathrm{E}-02$ & $4.35 \%$ \\
\hline SPMme & in w.g. & $8.76 \mathrm{E}-02$ & $5.46 \%$ \\
\hline SPFhe & in w.g. & $8.03 \mathrm{E}-02$ & $2.54 \%$ \\
\hline TPh & in w.g. & $4.13 \mathrm{E}-02$ & $-4.52 \%$ \\
\hline TPm & in w.g. & $5.42 \mathrm{E}-02$ & $-2.19 \%$ \\
\hline TPe & in w.g. & $6.92 \mathrm{E}-02$ & $-1.70 \%$ \\
\hline fhm & & $7.14 \mathrm{E}-04$ & $4.36 \%$ \\
\hline fme & & $1.03 \mathrm{E}-03$ & $5.47 \%$ \\
\hline fhe & & $4.49 \mathrm{E}-04$ & $2.56 \%$ \\
\hline
\end{tabular}

\section{Conclusions}

The observed pressure losses in the mid-end region were compared for the Flanged and

Quick-Fit ducts. There was no apparent difference in the observed profiles. By recursive back-calculation with the Colebrook equation, it was found that $\varepsilon \approx 0.0001$ feet for both types.

The entry loss factors determined from the data collected in this study show that the entry effects are still evident beyond $20 \mathrm{D}$ from the entry. This is apparent in the 4 inch duct, where the $F_{h}$ value at the hood (20 D) differs from that at the mid value, while the values determined at the mid and end locations are equal. The data for the 8 inch duct shows that the $\mathrm{F}_{\mathrm{h}}$ reaches a constant value by the mid measurement location (42 D). This proves McLoone's assumption that entry effects can still be observed past $20 \mathrm{D}$ from the entry and justifies his use of the section past $40 \mathrm{D}$ for determining the friction loss factors. Idelchik (Equation 10) recommended applying hydraulically smooth conditions based on the observed flow conditions. However, this pressure loss data showed that, particularly for higher velocities, but also for smaller diameters, this resulted in underestimating 
pressure losses. A recursive back-calculation through the Colebrook equation suggested using $\varepsilon=1 \times 10^{-4} \mathrm{ft}$ would be an appropriate value for selected duct types over the range of diameters and velocities tested. Using this value in the Colebrook equation predicted pressure losses similar to those determined using linear regression log models fitted for all diameters, both of which were better approximations than the Nikuradse equation. The predictive log model generated for specified diameters provided the closest approximation of the observed pressure losses.

The findings show that for the tested duct types/velocities the hydraulically smooth assumption did not accurately predict these observed pressure losses, even though the Idelchik inequality (Equation 10) suggested that hydraulically smooth equations were appropriate. Based on these findings, the best practice for predicting pressure losses is to either apply the Colebrook equation using the appropriate effective roughness for the given duct or to develop a log-model for the duct diameter of interest. An advantage of using a log model is that it does not involve an iterative solution for the $f$-value, though with current portable computers it is also easy to use the Colebrook equation in the field. 


\section{Bibliography}

Guffey, S. E. (1992) Friction Tables Determined from Colebrook's Equation for Standard Density Air Flow, Applied Occupational and Environmental Hygiene 7(7) (July 1992): pp 453-466

Guffey, S. E. (1990) Simplifying Pitot Traverses, Applied Occupational and Environmental Hygiene 5(2) (February 1990): pp 95-100

Wright, D. K., Jr. (1945) A New Friction Chart for Round Ducts, Transactions of the American Society of Heating and Ventilation Engineers vol. 51 Research Report No. 1280: pp 303-316

Hutchinson, F. W. (1953) Friction Losses in Round Aluminum Ducts, Transactions of the American Society of Heating and Ventilation Engineers vol. 59 Research Report No. 1469: pp 127-138

Colebrook, C. F. (1939) Turbulent Flow in Pipes, with particular reference to the Transition Region between Smooth and Rough Pipe Laws, Journal of the Institute of Civil Engineers vol. 2 Paper No. 5204: pp 133-156

Kemler, E. (1933) A Study of the Data on the Flow of Fluids in Pipes, Transactions of the American Society of Mechanical Engineers vol. 55 HYD-55-2: pp 7-32

Moody, L. F (1944) Friction Factors for Pipe Flow, Transactions of the American Society of Mechanical Engineers vol. 66 967-4124: pp 671-684

Huebscher, R. G. (1947) Friction Equivalents for Round, Square, and Rectangular Ducts, Transactions of the American Society of Heating and Ventilation Engineers vol. 54 Research Report No. 1329: pp 101-118

Schmieler, J. B., Houghten, F. C., and Olson, H. T. (1940) Analysis of the Factors Affecting Duct Friction, Transactions of the American Society of Heating and Ventilation Engineers vol. 46 Research Report No. 1154: pp 193-219

Savovic, Z., "Pressure Drop Calculation - Theory", pipeflowcalculations.com, 2008, Online Calculators, 09-Jan-2008 <http://www.pipeflowcalculations.com/pressuredrop/theory.htm>

Dejkam, A., "Pipe Pressure Loss Calculation Methods", arash.dejkam.com, 2007, Arash Dejkam, 25-Jan-2008 <http://arash.dejkam.com/software/pressure_loss/methods.php> 
Prandtl, L. von, (1933) Neuere Ergebnisse der Turbulenzforschung, Zeitschrift des Vereines Deutscher Ingenieure vol. 77 No. 5: pp 105-114

Blasius, H., (1913) Das Aehnlichkeitsgesetz bei Reibungsvorgängen in Flüssigkeiten, Mitteilungen über Forschungsarbeiten auf dem Gebiete des Ingenieurwesens vol. 131: pp 1-39

Nikuradse, J., (1933) Strömungsgesetze in rauhen Rohren, Forschung auf dem Gebiete des Ingenieurwesens vol 361: pp 1-22

Idelchik, I. E. Handbook of Hydraulic Resistance. 2nd ed. New York: Hemisphere Publishing Corp., 1986.

McLoone, H. E., Guffey, S. E., and Curran, J. P. (1993) Effects of Shape, Size, and Air Velocity on Entry Loss Factors of Suction Hoods, American Industrial Hygene Association Journal vol. 54 No 3: pp 87-94

American Conference of Governmental Industrial Hygenists, Committee on Industrial Ventilation: Industrial Ventilation, $20^{\text {th }}$ Edition, A Manual of Recommended Practice, Cincinnati, OH: ACGIH, 1988

Saph, A. V. and Schoder, E. H. (1903) An Experimental Study of the Resistances of the Flow of Water in Pipes, Transactions of the American Society of Civil Engineers vol. 51 Paper No. 964: pp 253-330

Guffey, S. E. (2008). HvMeasurement (Version 01 December '08) [Computer software]. Morgantown, WV: Heavent. Retrieved December 01, 2008. Available from http://industrialventilation.net

Moffat, R. J. (1988) Describing the Uncertainties in Experimental Results, Experimental Thermal and Fluid Science vol. 1 No 1: pp 3-17 


\section{Appendix A - Calculations}

If the local atmospheric pressure is not known, this can be estimated based on the

elevation (above sea level) as shown in Equation 20. The total (stagnation) pressure (Equation 21), saturation pressure of water vapor (Equation 22), and partial pressure of water vapor in moist air (Equation 23) are necessary to compute the humidity ratio of the air by Equation 24.

$$
\begin{gathered}
P_{b a r}=760 \times\left(1-6.73 \times 10^{-6} \times \text { Alt }\right)^{5.258} \\
\text { Where: } \\
\quad P_{\text {bar }}=\text { barometric pressure }(\mathrm{mm} \mathrm{Hg}) \\
\text { Alt }=\text { altitude above sea level }(\mathrm{feet}) \\
P_{\text {tot }}=\left(P_{\text {bar }}-1.868 S P_{\text {end }}\right) 133.32239
\end{gathered}
$$

Where:

$$
\begin{gathered}
\mathrm{P}_{\text {tot }}=\text { total (stagnation) pressure }(\mathrm{Pa}) \\
\mathrm{SP}_{\text {end }}=\text { static pressure at velocity measurement location }\left(\text { in } \mathrm{H}_{2} \mathrm{O}\right) \\
P_{w s}=\frac{e^{77.345+.0057 T^{-7}-7235 / T} d b}{T_{d b}^{8.2}}
\end{gathered}
$$

Where:

$\mathrm{P}_{\mathrm{ws}}=$ saturation pressure of water vapor $(\mathrm{Pa})$

$\mathrm{T}_{\mathrm{db}}=$ dry bulb temperature $(\mathrm{K})$

$$
P_{v}=P_{w s}-\frac{\left(P_{t o t}-P_{w s}\right)\left(T_{d b}-T_{w b}\right)}{\left(1555.56-0.722 T_{w b}\right)}
$$

Where:

$$
\begin{aligned}
\mathrm{P}_{\mathrm{v}} & =\text { partial pressure of water vapor in moist air }(\mathrm{Pa}) \\
\mathrm{T}_{\mathrm{wb}} & =\text { wet bulb temperature }(\mathrm{K}) \\
w=0.62198 & \frac{P_{v}}{P_{t o t}-P_{v}}
\end{aligned}
$$

Where:

$$
\mathrm{w}=\text { humidity ratio (mass of water / mass of dry air) }
$$

The density factor is given by Equations 25 . 


$$
D F=\frac{P_{b a r}+1.868 S P_{e n d}}{760 m m H g} \cdot \frac{294.25 K}{T_{d b}} \cdot \frac{1+w}{1+1.609 w}
$$

For each velocity pressure traverse point, the point velocity is calculated by Equation 26 . The average velocity $\left(\mathrm{V}_{\mathrm{avg}}\right)$ is the mean of the point velocities, from which the average velocity pressure $\left(\mathrm{VP}_{\mathrm{avg}}\right)$ is computed by means of the inverse of Equation 26 and the volumetric air flow rate is given by Equation 27.

$$
V_{j}=4005 \sqrt{\frac{V P_{j}}{D F}}
$$

Where:

$$
\begin{aligned}
\mathrm{V}_{\mathrm{j}}=\text { velocity at location } \mathrm{j} \\
\mathrm{VP}_{\mathrm{j}}=\text { velocity Pressure at location } \mathrm{j} \\
Q_{a c t}=V_{\text {avg }} \frac{\pi}{4} D_{h}
\end{aligned}
$$




\section{Appendix B - Excel User Defined Functions}

Function DensityFactor(SPend As Variant, Tdb As Variant, W As Variant, Optional Pbar

As Variant, Optional Alt As Variant) As Variant

If IsMissing(Pbar) Then

If IsMissing(Alt) Then

$\operatorname{Pbar}=760$

Else

$$
\begin{aligned}
& \text { DFalt }=\left(1-\text { Alt } * 6.73 / 10^{\wedge} 6\right) \wedge 5.258 \\
& \text { Pbar }=760 * \text { DFalt }
\end{aligned}
$$

End If

End If

$\mathrm{DFp}=((\mathrm{Pbar}+1.868 *$ SPend $) / 760)$

$\mathrm{DFt}=((273.15+21.1) /(273.15+\mathrm{Tdb}))$

$\mathrm{DFw}=((1+\mathrm{W}) /(1+1.609 * \mathrm{~W}))$

DensityFactor $=\mathrm{DFp} * \mathrm{DFt} * \mathrm{DFw}$

End Function

Function Humidity(Tdb As Variant, Twb As Variant, Optional Pbar As Variant, Optional SPend As Variant, Optional Alt As Variant) As Variant

Dim ptot As Double

Dim pws As Double

Dim pv As Double

$\mathrm{Tdb}=\mathrm{Tdb}+273.15$

$\mathrm{Twb}=\mathrm{Twb}+273.15$

If IsMissing(Pbar) Then 
If IsMissing(Alt) Then

Pbar $=760$

Else

DFalt $=\left(1-\text { Alt } * 6.73 / 10^{\wedge} 6\right)^{\wedge} 5.258$

Pbar $=760 *$ DFalt

End If

End If

If IsMissing(SPend) Then

$$
\text { ptot }=\text { Pbar * } 133.32239
$$

Else

$$
\text { ptot }=(\text { Pbar }+1.868 * \text { SPend }) * 133.32239
$$

End If

'ptot in $\mathrm{Pa}, \mathrm{Pbar}$ in $\mathrm{mmHg}$, SPend in inH2O

$$
\text { pws }=\operatorname{Exp}(77.345+0.0057 * \mathrm{Tdb}-7235 / \mathrm{Tdb}) / \mathrm{Tdb} \wedge 8.2 \text { 'Saturation pressure of }
$$
water vapor

$$
\mathrm{pv}=\mathrm{pws}-(\mathrm{ptot}-\mathrm{pws}) *(\mathrm{Tdb}-\mathrm{Twb}) /(1555.56-0.722 * \mathrm{Twb}) \text { ' Partial Pressure of }
$$

Water Vapor in Moist Air

Humidity $=0.62198 * \mathrm{pv} /(\mathrm{ptot}-\mathrm{pv})$

End Function

Function Reynolds(DF As Variant, V As Variant, Dh As Variant, Optional T As Variant) As Variant

Dim visc As Double 'viscosity in $1 \mathrm{bm}^{*} \mathrm{~s} / \mathrm{ft}^{\wedge} 2$

If IsMissing(T) Then

$$
\operatorname{visc}=3.82 * 10^{\wedge}-7
$$


Else

$\operatorname{visc}=-2.332 * 10^{\wedge}-15 * \mathrm{~T}^{\wedge} 3+7.466 * 10^{\wedge}-13 * \mathrm{~T}^{\wedge} 2+4.581 * 10^{\wedge}-10 * \mathrm{~T}+$ $3.426 * 10^{\wedge}-7$

End If

Reynolds $=0.0023769 * \mathrm{DF} * \mathrm{~V} * \mathrm{Dh} /$ visc

End Function

Function SPF_norm(f As Variant, VP As Variant, Dh As Variant) As Variant

$\mathrm{SPF} \_$norm $=\mathrm{f} * \mathrm{VP} / \mathrm{Dh}$

End Function

Function fBlasius(Re) As Double

If $\operatorname{Re}<10^{\wedge} 6$ Then

fBlasius $=0.3164 / \operatorname{Re}^{\wedge} 0.25$

Else

fBlasius $=0.014+1.8 /(\operatorname{Re}-2000)^{\wedge} 0.5$

End If

End Function

Function fPrandtl(Re As Variant) As Variant

fPrandtl $=1$

For $\mathrm{i}=1$ To 5

fPrandtl $=\left(2 * \log 10\left(\operatorname{Re}^{*} \text { fPrandtl } \wedge 0.5\right)-0.8\right)^{\wedge}-2$

Next i 
End Function

Function fNikuradse(Re As Variant) As Variant

fNikuradse $=0.0032+0.221 * \operatorname{Re}^{\wedge}-0.237$

End Function

Function fRough(Dh As Variant, Roughness As Variant) As Variant

$$
\text { fRough }=(2 * \log 10(3.7 * \mathrm{Dh} / \text { Roughness }))^{\wedge}-2
$$

End Function

Function fColebrook(Re As Variant, Dh As Variant, Roughness As Variant) As Variant

fColebrook $=1$

For $\mathrm{i}=1$ To 5

fColebrook $=\left(-2 * \log 10\left(\text { Roughness } / \mathrm{Dh} / 3.7+2.51 / \operatorname{Re} / \text { fColebrook }^{\wedge} 0.5\right)\right)^{\wedge}-2$

Next i

End Function

Function fHaaland(Re As Variant, Dh As Variant, Roughness As Variant) As Variant

$$
\text { fHaaland }=\left(-1.85 * \log 10\left(6.9 / \operatorname{Re}+(\text { Roughness } / \mathrm{Dh} / 3.7)^{\wedge} 1.11\right)\right)^{\wedge}-2
$$

End Function

Static Function $\log 10(\mathrm{X})$

$\log 10=\log (\mathrm{X}) / \log (10 \#)$

End Function 
Function eColebrook(Re As Variant, Dh As Variant, fact As Variant) As Variant

Dim e(1000), f(1000) As Double

Dim i, j As Integer

For $\mathrm{i}=0$ To 1000

$\mathrm{e}(\mathrm{i})=0.000001 * \mathrm{i}$

$\mathrm{f}(\mathrm{i})=1$

Next i

For $\mathrm{j}=0$ To 5

For $\mathrm{i}=0$ To 1000

$\mathrm{f}(\mathrm{i})=\left(-2 * \log 10\left(\mathrm{e}(\mathrm{i}) / \mathrm{Dh} / 3.7+2.51 / \mathrm{Re} / \mathrm{f}(\mathrm{i})^{\wedge} 0.5\right)\right)^{\wedge}-2$

Next i

Next j

For $\mathrm{i}=0$ To 1000

If $\mathrm{f}(\mathrm{i})<=$ fact Then

eColebrook $=\mathrm{e}(\mathrm{i})$

End If

Next $\mathrm{i}$

End Function 